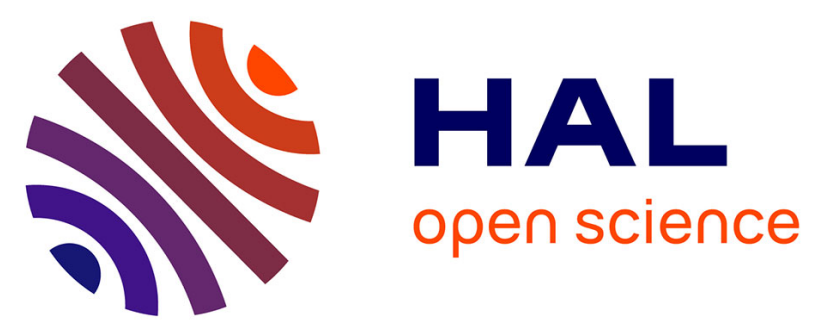

\title{
Experimental Hydrodynamic Study of Gas-Particle Dense Suspension Upward Flow for Application as New Heat Transfer and Storage Fluid
}

Benjamin Boissière, Renaud Ansart, Daniel Gauthier, Gilles Flamant, Mehrdji Hemati

\section{To cite this version:}

Benjamin Boissière, Renaud Ansart, Daniel Gauthier, Gilles Flamant, Mehrdji Hemati. Experimental Hydrodynamic Study of Gas-Particle Dense Suspension Upward Flow for Application as New Heat Transfer and Storage Fluid. Canadian Journal of Chemical Engineering, 2014, pp. 1-14. 10.1002/cjce.22087 . hal-01101789

\author{
HAL Id: hal-01101789 \\ https://hal.science/hal-01101789
}

Submitted on 9 Jan 2015

HAL is a multi-disciplinary open access archive for the deposit and dissemination of scientific research documents, whether they are published or not. The documents may come from teaching and research institutions in France or abroad, or from public or private research centers.
L'archive ouverte pluridisciplinaire HAL, est destinée au dépôt et à la diffusion de documents scientifiques de niveau recherche, publiés ou non, émanant des établissements d'enseignement et de recherche français ou étrangers, des laboratoires publics ou privés. 


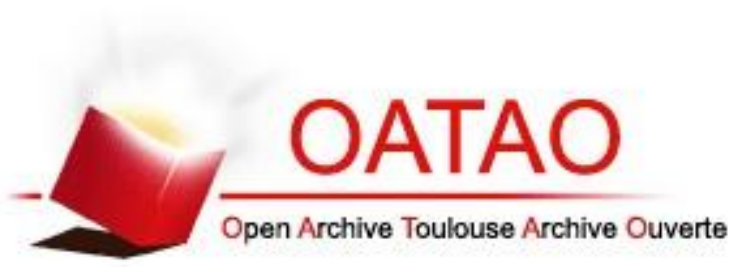

Open Archive Toulouse Archive Ouverte (OATAO)

OATAO is an open access repository that collects the work of Toulouse researchers and makes it freely available over the web where possible.

This is an author-deposited version published in: http://oatao.univ-toulouse.fr/ Eprints ID: 12254

Identification number: DOI : 10.1002/cjce.22087

Official URL: http://dx.doi.org/10.1002/cjce.22087

\section{To cite this version:}

Boissière, Benjamin and Ansart, Renaud and Gauthier, Daniel and Flamant, Gilles and Hemati, Mehrdji Experimental Hydrodynamic Study of Gas-Particle Dense Suspension Upward Flow for Application as New Heat Transfer and Storage Fluid. (2014) Canadian Journal of Chemical Engineering . pp. 1-14. ISSN 0008-4034

Any correspondence concerning this service should be sent to the repository administrator: staff-oatao@inp-toulouse.fr 


\title{
EXPERIMENTAL HYDRODYNAMIC STUDY OF GAS-PARTICLE DENSE SUSPENSION UPWARD FLOW FOR APPLICATION AS NEW HEAT TRANSFER AND STORAGE FLUID
}

\author{
Benjamin Boissiere, ${ }^{1,2 *}$ Renaud Ansart, ${ }^{1,2}$ Daniel Gauthier, ${ }^{3}$ Gilles Flamant ${ }^{3}$ and Mehrdji Hemati ${ }^{1,2}$ \\ 1. Université de Toulouse, INPT, UPS, Laboratoire de Génie Chimique, 4, Allée Emile Monso F-31030, Toulouse, France \\ 2. CNRS, Laboratoire de Génie Chimique, F-31030, Toulouse, France \\ 3. CNRS, Laboratoire PROMES, 7 Rue du Four Solaire 66120, Font-Romeu Odeillo, France
}

This paper focuses on a new concept of Heat Transfer Fluid (HTF) for Concentrating Solar Plants (CSP) applications through fluidized bed. CSP plants with very high concentration (such as solar tower plant technology) offer good efficiencies because of high operating temperatures. CSP efficiency could be greatly increased through more efficient HTF. Molten salts, mineral oils, water and air have some of the following drawbacks: limited range of operating temperatures, corrosiveness, high pressure, low energy storage capacity and toxicity.

To replace classical HTF, Dense Particle Suspension (DPS) fluidized with air (approximately $40 \%$ of solid) is proposed. DPS has a volume heat capacity similar to those of liquid HTF, does not need pressurization, is safe, inert and is only limited by the maximal working temperature of the receiver material $(1100 \mathrm{~K})$, thus opening new opportunities for high efficiency thermodynamic cycles. This work is the hydrodynamic study of a gassolid dense suspension upward flow at ambient temperature, in a vertical 2-tube bundle of small diameter tubes, which have their bottom immersed in a slightly pressurized fluidized bed (pressure approximately equal to the ratio of the solid weight in a tube over its cross section area). This type of flow is yet implemented in the field of hyper-dense phase vertical conveying of powders and it is currently under development for solar receivers using dense suspensions of particles as heat transfer and storage medium. This application was patented by Flamant and Hemati in 2010 (France 1058565 (2010) CNRS/INP Toulouse, G. Flamant, H. Hemati; PCT Extension, No. WO 2012/052661 A2), and its development is funded by the European Commission. In this technological breakthrough, the concentrated solar energy is collected, carried and stored directly by the fine particles flowing upward, with a suspension void fraction close to that of a dense fluidized bed. Contrary to circulating fluidized bed "risers", it offers a good contact area between the wall and the particles.

The important hydrodynamic and thermal coupling required a step-by-step approach. Ambient flows had to be understood and controlled first. Thus a 2-pass "cold" mock-up, each pass composed of two vertical parallel tubes, was built. Pressure drop, solid weight and helium volume fraction measurements demonstrated the ability to handle a regular solid upward flow (imperative here), with solid flow rates from 20 to 130 kg.h ${ }^{-1}$, with void fractions from 0.57 to 0.63 and with an even distribution of the solid flow rate between the tubes. Moreover, the governing parameters of this flow were established as: the solid feeding flow rate, the fluidization velocity, the solid holdup, the freeboard pressure and the aeration velocity. The secondary air injection, also called "aeration", is the most important parameter for the stability and the even distribution of the total solid flow rate in the tubes. The 1D modelling of the suspension flow in the tubes was also performed in the flow direction. The flow structure was described using the bubble-emulsion model formalism, and by adding the solid entrainment by the bubble wake. Predictions of the model are compared with the experimental measurements of driving pressure and axial pressure profile along the tubes.

Keywords: fluidization, fine particles (A/B-type), dense particle suspension, upward flow, heat transfer media

\section{INTRODUCTION}

\section{Background and Key Issues}

Renewable energies are today one of the most common topics of Research. European Union leaders reached agreement in principle in March 2007 that $20 \%$ of the bloc's final energy consumption should be produced from renewable energy sources by 2020 as part of its drive to cut or reduce carbon dioxide emissions. The success of this commitment will partially come from the increase of the renewable energy plant efficiency.

Among renewable energies, solar energy offers low risks, long lifetime, no fossil fuel consumption, very low carbon dioxide emissions, great spread production, high power production and unlimited resource. In the field of high concentration, the efficiency of solar energy conversion increases with the size and the solar concentration factor.

Regarding the field of high-concentration solar industry, a great improvement could come from the ability to operate at higher temperatures that offer better efficiencies through the use of supercritical steam cycles. ${ }^{[1]}$ Current industrial heat transfer fluids (HTF) are molten salts, mineral oils, steam and air at atmospheric pressure (pressurized air is under development). Among them, molten salts are mainly used in concentrated solar power (CSP) plants like solar towers because they have a very good heat transfer coefficient and their cost is relatively low, ${ }^{[2,3]}$ but the upper limit of operating temperature (typically $840 \mathrm{~K}$ for binary sodiumpotassium nitrate salt) has an impact on the plant efficiency. Then the temperature must be maintained higher than $510 \mathrm{~K}$ because of the risk of solidification, which implies energy consumption when there is no solar input (night, cloudy day). Moreover, they are corrosive. Mineral oils are mainly used in lower concentration solar plants such as parabolic or linear Fresnel reflector power plants, and they suffer from many drawbacks. They have a limited range of operating temperature, they are corrosive and potentially

\footnotetext{
*Author to whom correspondence may be addressed. E-mail: address: benjamin.boissiere@ensiacet.fr Can. J. Chem. Eng. 9999:1-14, 2014
}

DOI 10.1002/cjce.22087 
carcinogenic. Steam needs dangerous and hardly manageable high pressure and air suffers from its low heat transfer capacity. Other prospective options such as liquid metals offer high flux limit on the receiver and extended operation to temperatures higher than $840 \mathrm{~K}$, as described by Pacio and Wetzel, ${ }^{[4]}$ but they are highly corrosive.

In October 2010, Flamant and Hemati patented the concept of using dense particle suspensions (DPS) (approximately $40 \%$ of solid volume fraction) as a new heat transfer fluid and storage medium. This concept is to create a gas-solid dense suspension upward flow, in a vertical bundle of small diameter tubes, which have their bottom immerged in a slightly pressurized fluidized bed (pressure approximately equal to the ratio of the solid weight in a tube over its cross section area). This type of flow is yet implemented in the field of hyper-dense phase conveying of powders and it is currently under development for solar receivers using DPS as heat transfer and storage medium. The study of this technological breakthrough was first financially supported by CNRS (PIE PARTISUN Project), and it is currently funded by the European Commission through the CSP2 Project - Concentrated Solar Power in Particles. ${ }^{[5]}$ Three different mock-ups and a 16-tube pilot of $150 \mathrm{~kW}_{\text {th }}$ were built in the frame of this project with the aim of demonstrating the workability of the proposed innovation.

A general diagram of a solar tower using dense suspensions of particles is given in Figure 1. The loop is composed of a solar receiver (dense particle suspension heat collector (DPSHC)) transferring the solar radiation energy to the DPS. A hot storage tank collects the heated particles and feeds the Fluidized Bed Heat Exchanger (FBHE) where the particles transmit their energy to a working fluid (for example steam) inside submerged tubes. The latter is then expanded in a turbine. FBHE is indeed a classical device in the electrical power industry (mostly implemented for coal combustion in fluidized bed). The cooled particles exit the exchanger (continuous circulation) and flow to the cold storage tank; this can be done either by mechanical or pneumatic conveying or by gravity depending on the available space or on the facility geometry (tower configuration is particularly favourable to gravity transfer). Finally, the particles are raised in the DPSHC by a conveying system. Consequently, solid particles are used as both heat transfer fluid and heat storage medium. In this concept, the DPSHC is the key component.

Tubular absorbers are mainly used in current solar thermal plants. The DPSHC receiver presented hereafter is also composed of

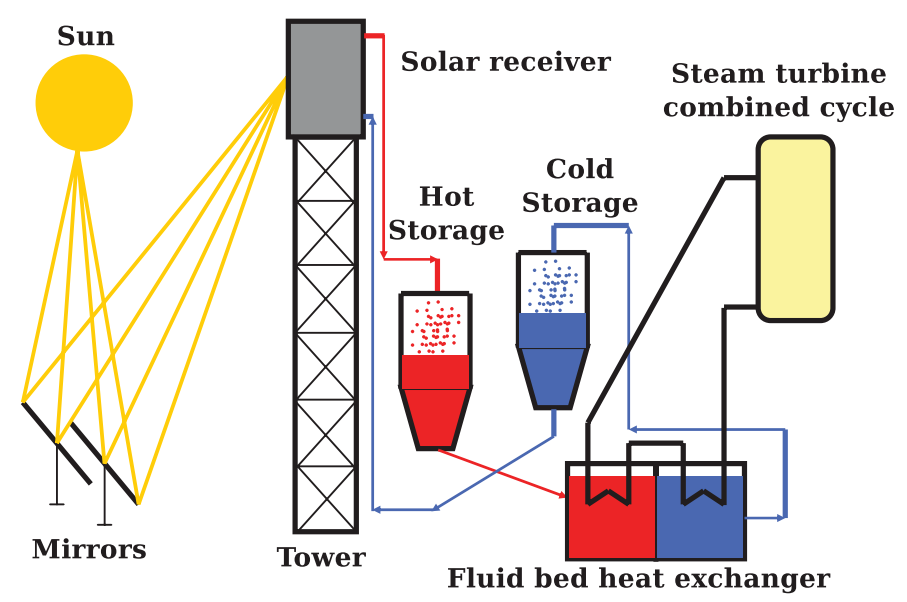

Figure 1. Principle of the conversion loop implementing particle solar receiver. vertical tubes. Solid particles associated with solar tower concentrating systems offer very interesting options for high temperature and high efficiency power cycles, thermal storage integration (since using the same particles as HTF and storage medium) and chemical applications of concentrated solar energy (thermo-chemical water splitting to produce hydrogen or cement processing, for example).

The properties of solids and moreover of fluidized beds have raised interest in the solar field and the combination of both is not new. Indeed, solids can stand very high temperatures before melting ( $1600 \mathrm{~K}$ for silicon carbide for example) and fluidized beds have good thermal exchange properties. As an illustration, the solar-powered fluidized bed gasifier of carbonaceous material patented by Qader and Robert in 1980 may be cited. ${ }^{[6]}$ DPS are also used in concentrated solar field to heat gas at high temperature or to produce hydrogen, but not directly as a heat "transfer" and "storage" medium. ${ }^{[7,8]}$ In this new concept, the particles are fluidized and flowed as a suspension in the vertical tubes that constitute the receiver. The solid flow can be either upward or downward. On-sun tests performed by Flamant et al. dealing with DPS thermal exchange efficiency has led to approximately $250 \mathrm{~W} \cdot \mathrm{m}^{-1} \cdot \mathrm{K}^{-1}$ of wall-to-suspension heat exchange coefficient and they demonstrated the concept validity. ${ }^{[9]}$

As presented hereafter, there exists numerous vertical flow patterns of particles carried out by a gas. The particle flow properties such as solid flow rate, gas flow rate and solid volume fraction of the suspension are decisive for the suspension properties in terms of heat transfer. The favourable heat transfer properties of dense suspensions with void fraction close to that of a fluidized bed justify the implementation of vertical flow of dense suspensions in the following study.

\section{Gas-Particle Suspensions Upward Flows}

As demonstrated by Tavares, ${ }^{[10]}$ downward flows of dense gasparticle suspensions are hardly manageable. These authors showed that the gas compression must be compensated by staged aeration of the standpipe to avoid de-fluidization and solid plugging. Therefore, this study is focused on DPS upward flow that is easier to operate.

The flow chart for gas-solid upward transport displayed in Figure 2 presents the various solid upward flows by increasing the gas velocity at constant solid circulation rate. It puts into evidence

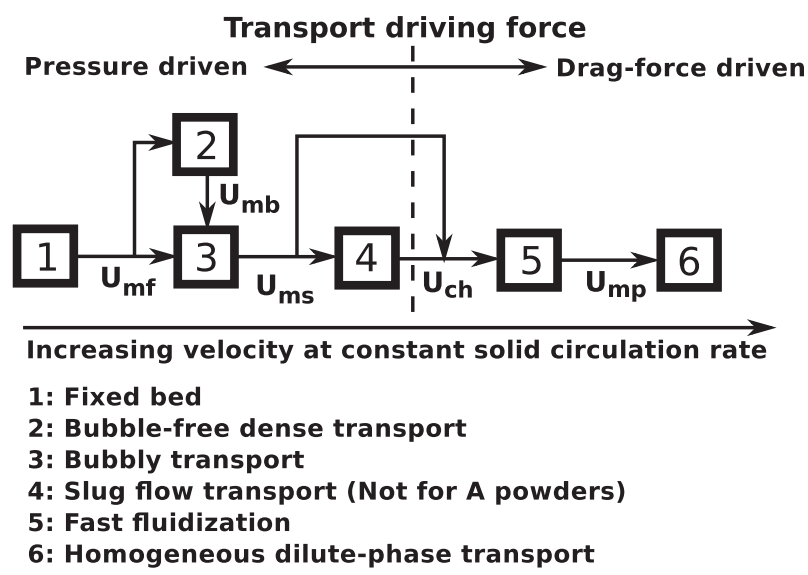

Figure 2. Flow-chart for gas-solid upward transport: $U_{\mathrm{mf}}$ minimum fluidization velocity, $U_{m b}$ minimum bubbling velocity, $U_{m s}$ minimum slugging velocity, $U_{c h}$ chocking velocity, $U_{m p}$ minimum velocity for dilute pneumatic conveying. 
two zones: a pressure-driven zone for low gas velocities and a dragforce driven zone at higher gas velocities. The frontier between these two zones is the chocking velocity $U_{c h}$. The flow generated in the mock-up presented hereafter is a pressure-driven flow, particularly a bubbly transport flow.

The background on gas-solid conveying in tubes is rich regarding Circulating Fluidized Beds (CFB) technology. It corresponds to fast fluidization and homogeneous dilute-phase transport presented in Figure 2. CFB are well-developed industrially at large scale in oil refineries and in combustion plants. For example, in Fluid Catalytic Cracking (FCC) process in petroleum refineries, solid catalytic flow rate as high as $2000 \mathrm{~T} . \mathrm{h}^{-1}$ is typical in a single reactor. Generally, reactors (riser) operate at high gas velocity (several $\mathrm{m} . \mathrm{s}^{-1}$ ) and dilute solid gas flows (solid fraction less than $1 \%)$. Consequently, CFB requires high mechanical energy consumption for compression while the low solid fraction leads to a poor wall-to-particles heat exchange coefficient. Moreover, the particle high velocities provoke tube erosion and solid particle attrition. So, such a solid flow is not suitable for solar applications, and it is planned contrarily to operate with low gas velocity and high solid volume fraction.

Various flows of gas-particle suspension under dense state are implemented industrially. At lower gas velocity (for the same solid flow rate), there exists plug-flow pneumatic conveying that allows transporting solid at lower velocities and higher average volume fraction, as shown by Watson et al. ${ }^{[11]}$ However, this regime is mainly characterized by an alternation between solid plugs with a void fraction close to that of a settled bed and voids with almost no solid, which is not an appropriate configuration for efficient heat transfer.

The bubbly upward flow of DPS fluidized with air in tubes has already been studied by Turzo et al. in the frame of collaboration with the Rio Tinto Alcan company. ${ }^{[12]}$ This work demonstrated the upward flow achievability of dense suspensions of A Geldart group particles fluidized with air in tubes of 28 and $56 \mathrm{~mm}$ of inner diameter and $6 \mathrm{~m}$ long.

As explained earlier, the concept validity was proved in a onetube mock-up and has now to be extrapolated to a tube bundle. ${ }^{[9]}$ The "cold" hydrodynamic study of DPS upward flow in several parallel tubes is then useful.

The solid flow rate must be continuous, stable and evenly parted in the tubes in order to avoid overheating and risk of melting of the receiver tubes. The solid flow rate must also be quickly modifiable to fit the incident solar flux changes.

In the presented set-up, the solid velocity in the $34 \mathrm{~mm}$ i.d. tubes ranges from $0.5 \mathrm{~cm} . \mathrm{s}^{-1}$ to $3 \mathrm{~cm} . \mathrm{s}^{-1}$, and the superficial gas velocity from $1 \mathrm{~cm} . \mathrm{s}^{-1}$ to $6 \mathrm{~cm} . \mathrm{s}^{-1}$. Although solid velocities are low, the solid flow rate ranges from $20 \mathrm{~kg} \cdot \mathrm{h}^{-1}$ to $130 \mathrm{~kg} \cdot \mathrm{h}^{-1}$ since the suspension is dense. The produced flow is similar to a moving up bubbling bed.

A great number of published papers deal with the upward transport of dilute gas-solid suspensions by either fast fluidization, or core-annular dilute phase flow or homogeneous dilute phase flow (by increasing gas velocity) ${ }^{[13,14]}$ whereas very few papers address the upward flow of dense or concentrated gas-solid suspensions. Those dealing with gaseous transport of highlyconcentrated solid are at the limit between fast fluidization and bubbly transport or fixed bed dense phase transport, and aim at mapping the flow regime depending on different flow parameters, such as column diameter, particle size and density, gas flow rate and solid flow rate. ${ }^{[15,16,17]}$

In the following section, we present the various dense upward flow regimes and their associated terminology.

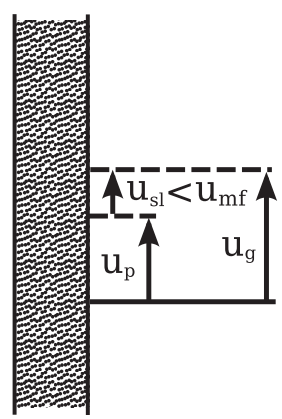

(a)

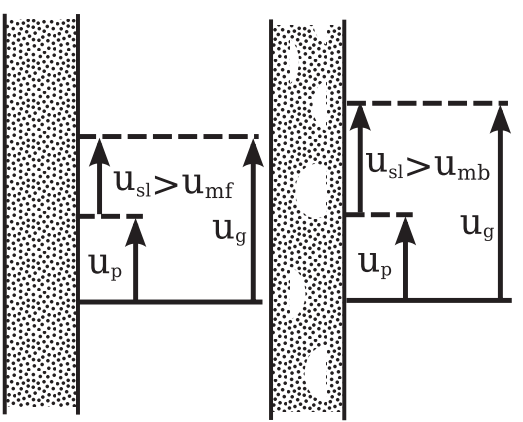

(b)

(c)
Figure 3. Flow regimes of dense upward flows: (a) moving up packed bed, (b) homogeneous upward flow, (c) heterogeneous upward flow.

\section{The Different DPS Upward Flow Regimes}

The different regimes are defined for a classical fluidized bed regarding the slip velocity between gas and solid. Equation (1) gives the slip velocity $u_{s l}$ defined as the difference between the gas local velocity $u_{\mathrm{g}}$ and the solid local velocity $\mathrm{u}_{\mathrm{p}}$. In a fluidized bed, the interstitial gas velocity directly gives the slip velocity, but the positive cross-section averaged particle velocity must be considered for a DPS upward flow. In fluidized beds, the suspension behaviour mainly depends on the local slip velocity:

$u_{s l}=u_{g}-u_{p}$

The first classification of the vertical flow of gas-particle suspensions was proposed by Zenz. ${ }^{[18]}$ He differentiated the nonfluidized state when the slip velocity $u_{s l}$ is lower than the minimum fluidising velocity $\mathrm{u}_{\mathrm{mf}}$ (also called packed bed), and the fluidized state in the opposite case.

Similarly to the classical fluidized bed of A or A/B Geldart group particles, the suspension is said homogeneous (free of bubbles) when the slip velocity is between the minimum fluidising velocity and the minimum bubbling velocity. When the slip velocity exceeds the minimum bubbling velocity, bubbles appear: the excess gas goes through the suspension as bubbles. The three regimes (packed bed, bubble-free dense fluidized bed and bubbling bed) are represented in Figure 3.

The particle agitation generated by bubbles of the heterogeneous flow is favourable to heat exchange between the receiver wall and the particles. So, the heterogeneous regime is preferable for concentrated solar applications as it was shown by Bataille and Flamant. ${ }^{[19,20]}$ The heat exchange is conditioned by hydrodynamics through the recovery rate and the renewal rate of particles at the wall. The accurate hydrodynamic characterization of the DPS flow under ambient conditions is then fundamental. It involves the determination of governing parameters for a stable, adjustable and evenly distributed solid flow in parallel tubes.

\section{DESCRIPTION OF THE EXPERIMENTAL SET-UP}

\section{Material and Methods}

The selection of the powder was based on two criteria: its nature and its grain size. Its nature was determined on the expected physical properties and its grain size was then selected from its fluidization properties.

The powder must have the best heat storage capacity, the highest maximum working temperature, a good thermal conductivity, a 
very low attrition and a low cost. Based on these criteria, the silicon carbide was selected.

The grain size must offer a good fluidization with low gas velocities, meaning low gas-compression energy consumption. It corresponds to particles that stand at the frontier between A and B groups of Geldart classification. As silicon carbide density is $3210 \mathrm{~kg} \cdot \mathrm{m}^{-3}$, the particle size has to be less than about $60 \mu \mathrm{m}$. Figure 4 is a SEM photograph of the selected powder.

The minimum fluidization velocity $\mathrm{u}_{\mathrm{mf}}$, the minimum bubbling velocity $\mathrm{u}_{\mathrm{mb}}$ and their associated void fractions $\varepsilon_{\mathrm{mf}}$ and $\varepsilon_{\mathrm{mb}}$ were experimentally determined and are reported in Table 1 . The minimum fluidization velocity corresponds to the velocity at which occurs a slope break of the curve plotting the bed pressure drop versus the gas velocity. The minimum bubbling velocity is the velocity of the closest local minimum of the bed pressure drop profile in Figure 5.

\section{Experimental Set-up}

The mock-up detailed in Figure 6 was designed and assembled in the Laboratoire de Génie Chimique de Toulouse premises. It was designed to be tested under ambient temperature. Thus, the fluidized beds and the exchanger tubes are transparent, which makes operation easier. The two parallel vertical tubes are immerged in the emitter fluid bed (bottom bed). The pressurization of the emitter bed generates the DPS ascension in the tubes. The solid goes from the hopper to the solid outlet (connected to a recovery vessel) making this exchanger an open-loop system. Following the solid path, the components of the mock-up are, successively,

- the hopper that can store $250 \mathrm{~kg}$ of silicon carbide;

- the screw feeder that feeds the fluidized bed at its bottom, with a constant flow rate of solid $F_{p}$ ranging from $20 \mathrm{~kg} \cdot \mathrm{h}^{-1}$ to $130 \mathrm{~kg} \cdot \mathrm{h}^{-1}$;

- the fluidized bed at the bottom, also called emitter bed (width $400 \mathrm{~mm}$, depth $200 \mathrm{~mm}$ and height $400 \mathrm{~mm}$ above the sintered metal plate distributor), which contains about $30 \mathrm{~kg}$ of solid;

- the tubes, plunging in the emitter bed down to $5 \mathrm{~cm}$ from the distributor (the tubes are $2.16 \mathrm{~m}$ high, $34 \mathrm{~mm}$ i.d. and $40 \mathrm{~mm}$ o.d.).

A gas injection nozzle for aeration is set on each tube at $0.57 \mathrm{~m}$ from the tube bottom. The top bed has the same dimensions

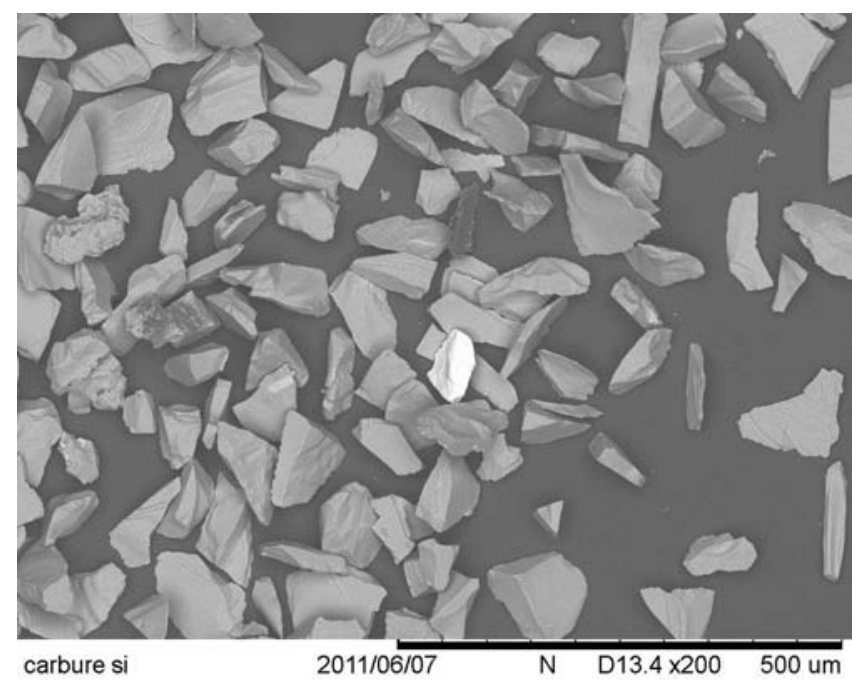

Figure 4. SEM photograph of the selected silicon carbide particles $(48 \times)$.
Table 1. Physical and hydrodynamic properties of silicon carbide: particle density checked by water pycnometry, diameters and Particle Size Distribution (PSD) determined by laser granulometry (Mastersizer 2000: dispersion pressure of 2 bars), fluidization properties experimentally determined on a $19.2 \mathrm{~cm}$ diameter column (woven distributor), and other properties determined with the Hosokawa Powder Tester apparatus

\begin{tabular}{ll}
\hline Physical properties & \\
$\mathrm{d}_{10}[\mu \mathrm{m}]$ & 44 \\
$\mathrm{~d}_{50}[\mu \mathrm{m}]$ & 79 \\
$\mathrm{~d}_{90}[\mu \mathrm{m}]$ & 130 \\
$\mathrm{~d}_{32}[\mu \mathrm{m}]$ & 64 \\
$\rho_{\mathrm{p}}\left[\mathrm{kg} \cdot \mathrm{m}^{-3}\right]$ & 3210 \\
$\lambda\left[\mathrm{W} \cdot \mathrm{m}^{-1} \cdot \mathrm{K}^{-1}\right]$ & $114(300 \mathrm{~K})$ \\
& $35(1300 \mathrm{~K})$ \\
$\mathrm{C}_{\mathrm{p}, \mathrm{m}}\left[\mathrm{k} \cdot \mathrm{kg}^{-1} \cdot \mathrm{K}^{-1}\right]$ & $0.67(300 \mathrm{~K})$ \\
$\mathrm{T}_{\text {melting }}[\mathrm{K}]$ & $1.26(1300 \mathrm{~K})$ \\
$\mathrm{T}_{\text {max }}[\mathrm{K}]$ & 2730 \\
$\mathrm{Hydrodynamic}$ properties & 1300 \\
$\mathrm{U}_{\mathrm{mf}}\left[\mathrm{mm} \cdot \mathrm{s}^{-1}\right]$ & \\
$\varepsilon_{\mathrm{mf}}$ & 5.0 \\
$\mathrm{U}_{\mathrm{mb}}\left[\mathrm{mm} \cdot \mathrm{s}^{-1}\right]$ & 0.57 \\
$\varepsilon_{\mathrm{mb}}$ & 8.0 \\
Angle of repose $\alpha_{\mathrm{r}}$ & 0.59 \\
Angle of fall $\alpha_{\mathrm{f}}$ & $36.5^{\circ}$ \\
Aerated bulk density $\left[\mathrm{kg} \cdot \mathrm{m}^{-3}\right]$ & 18.9 \\
Packed bulk density $\left[\mathrm{kg} \cdot \mathrm{m}^{-3}\right]$ & 1419 \\
Carr index & 1610 \\
\hline
\end{tabular}

than the emitter bed and is placed rearmost as shown in Figure 7. The air connection between the hopper and the emitter bed equals their pressure thus allowing the solid feeding of the emitter bed by the screw feeder. The pressurization of the emitter fluid bed is ensured by a pneumatic valve connected to a PID controller.

\section{Metrology}

Pressure sensors are placed as shown on Figure 8. Those along the pipes $\left(n^{\circ} 1\right.$ to $\left.n^{\circ} 8\right)$ determine the local gas pressure drop of the suspension and thus estimate the suspension state (void fraction).

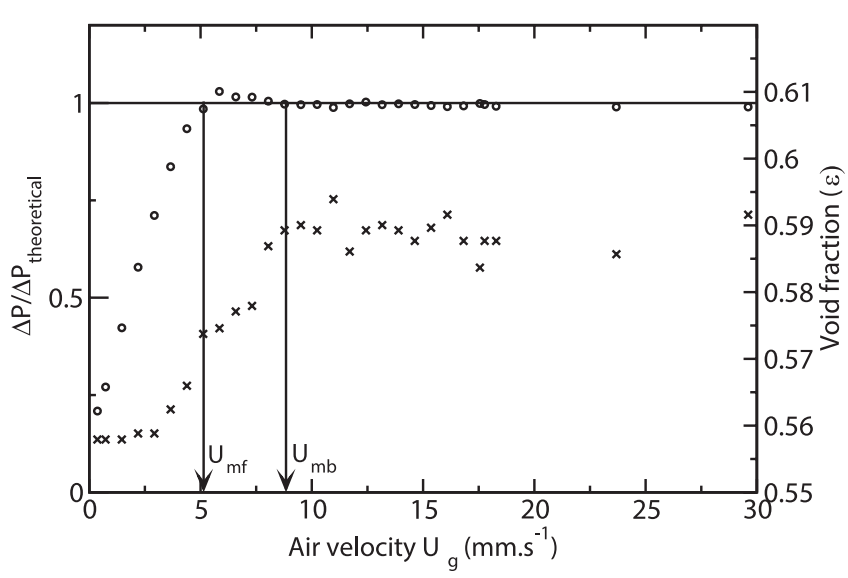

Figure 5. Fluidization curve of $\mathrm{SiC}$ powder $\left(\mathrm{d}_{32}=64 \mu \mathrm{m}\right)$; theoretical pressure drop $=135$ mbars, $(x)$ bed void fraction determined from bed height measurements, (o) gas pressure drop of the bed normalized by the theoretical pressure drop of the bed. 


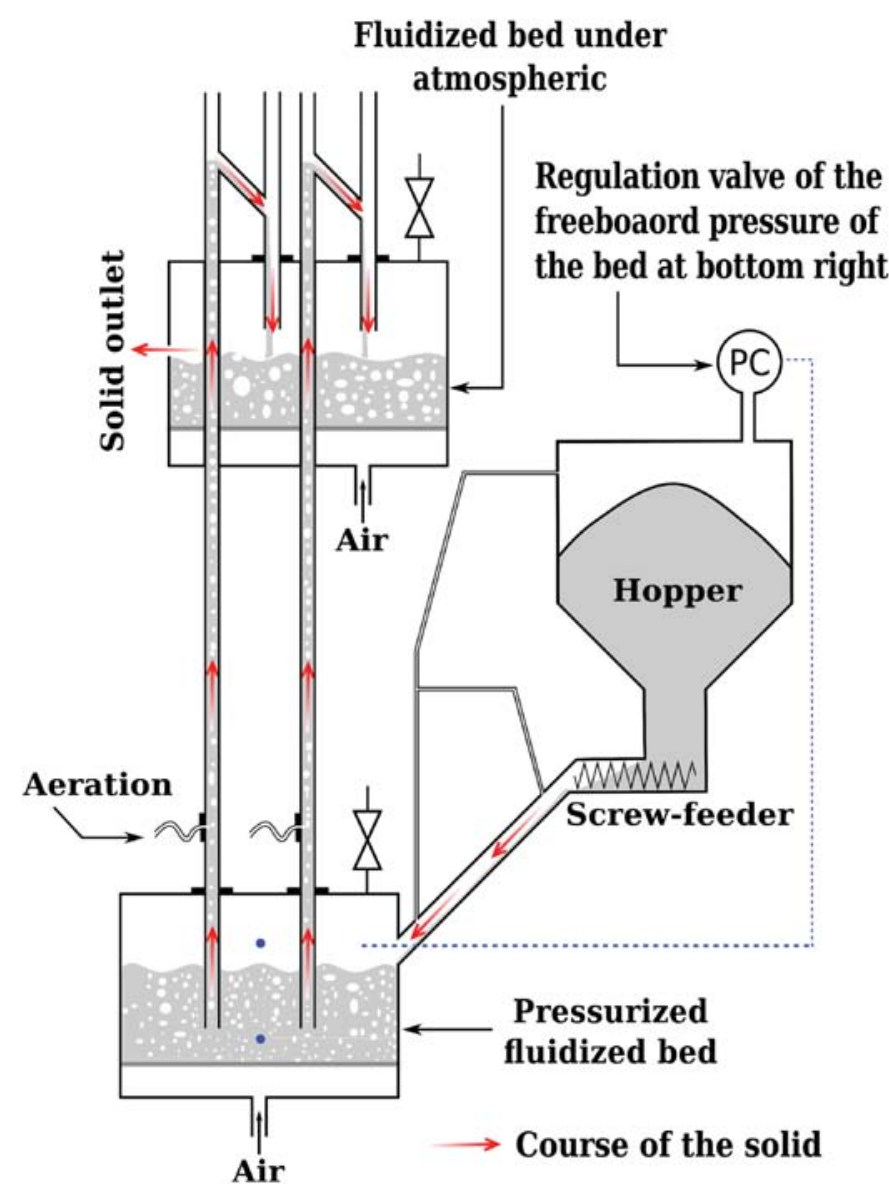

Figure 6. Sketch of the "cold" mock-up.

The solid holdup of the emitter bed is calculated from the gas pressure drop measured by the pressure sensor $n^{\circ} 9$. It gives the bed hydrostatic pressure $\Delta \mathrm{P}_{\text {bed }}$. A steady emitter bed solid holdup means that the sum of both solid flow rates ( 2 tubes) equals the constant solid feeding flow rate of the emitter bed (by screw feeder). The solid flow stability in the tubes corresponds to the emitter bed solid holdup stability.

The study of the coupling between the emitter bed and the vertical tubes was performed by injecting a known flow rate of helium $\mathrm{Q}_{\mathrm{He}}$ in the aeration tap and by tracing it at the tube outlet. The tracing device includes air and helium mass flow meters, a mixer and a helium volume fraction analyser. The helium tracing of the gas phase first demonstrated that the gas flow in the tubes is only upward. Then, the helium volume fraction $\mathrm{y}_{\mathrm{He}}$ was only measured at the tube outlet.

The total gas flow rate going through the vertical tubes was estimated through the mass conservation law of helium expressed by Equation (2). $\mathrm{y}_{\mathrm{He}, \mathrm{f}}$ is the time-averaged helium volume fraction value measured during 30 minutes of steady state. The gas flow rate exchanged between the emitter bed and the tubes is deduced by subtracting the aeration and helium flow rates from the total gas flow rate:

$Q_{b t}=\frac{Q_{H e}}{y_{H e, f}}-Q_{H e}-Q_{a e}$.

$\mathrm{Q}_{\mathrm{ae}}$ represents the aeration flow rate, $\mathrm{Q}_{\mathrm{He}}$ the helium flow rate, $\mathrm{y}_{\mathrm{He}}$ the helium volume fraction and $\mathrm{Q}_{\mathrm{bt}}$ the air flow rate exchanged between the emitter bed and the tubes.

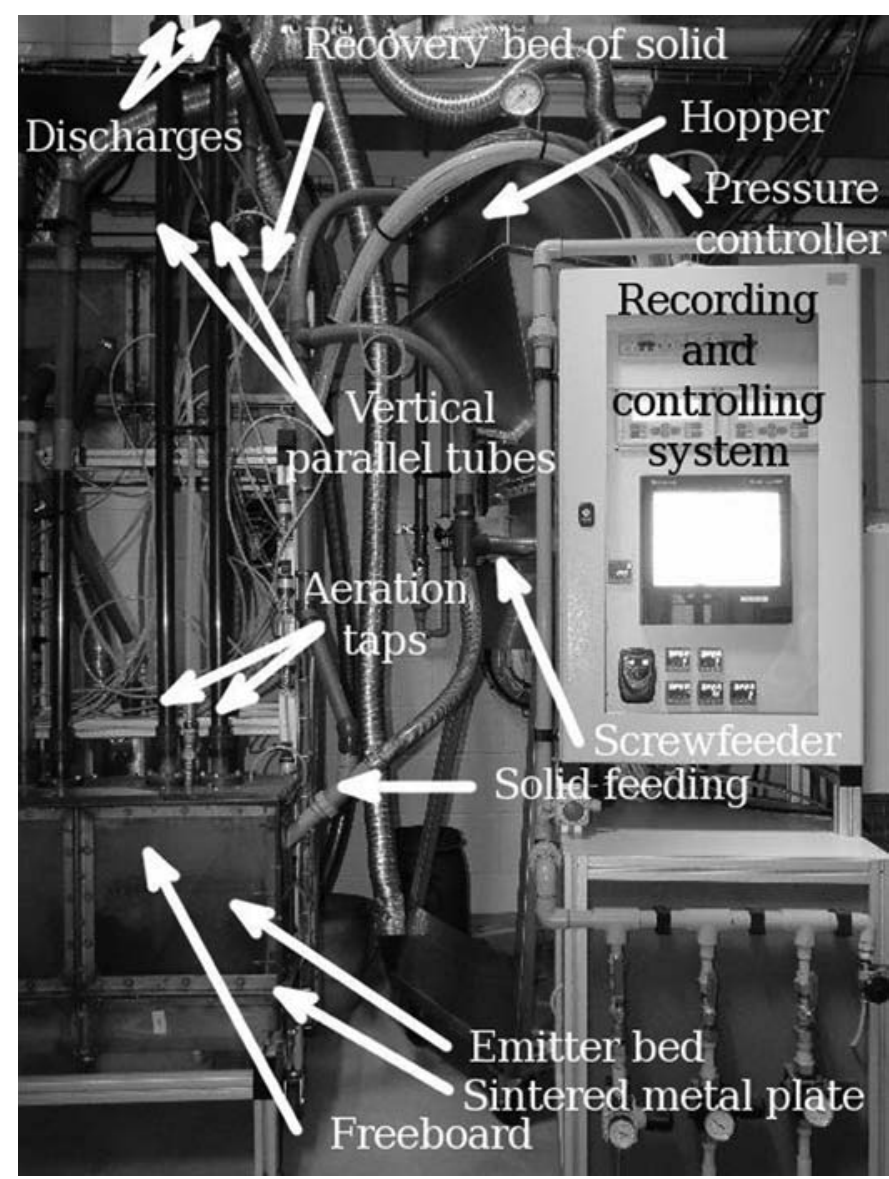

Figure 7. Photograph of the cold mock-up.

\section{Operating Parameters}

A gas velocity $U_{f}$ slightly higher than the minimum bubbling velocity fluidizes the emitter bed. Pressuring the emitter bed induces the solid ascension in the tubes. The operating parameters are the solid feeding flow rate of the emitter bed by the screw feeder $\left(F_{p}\right)$, the fluidization flow rate of the emitter bed $\left(Q_{f}\right)$, the aeration flow rate of the tubes $\left(Q_{a e}\right)$ and the pressure of the emitter bed freeboard $\left(\mathrm{P}_{\mathrm{fb}}\right)$.

The solid flow driving force in the tubes is the pressure difference between the pressure at the tube inlet $\left(P_{\text {in }}\right)$ and the atmospheric pressure:

$\Delta \mathrm{P}_{\text {drive }}=\mathrm{P}_{\text {in }}-\mathrm{P}_{\text {out }}=\mathrm{P}_{\text {in }}-\mathrm{P}_{\mathrm{atm}}$.

$P_{\text {in }}$ equals the pressure of the emitter bed freeboard $\left(P_{f b}\right)$ added to the hydrostatic pressure due to the bed height from its top to the tube inlet level $\left(\Delta \mathrm{P}_{\text {bed }}\right) . \mathrm{F}_{\mathrm{p}}, \mathrm{Q}_{\mathrm{f}}, \mathrm{Q}_{\mathrm{ae}}, \mathrm{P}_{\mathrm{fb}}$ are asset constant during a test. As $P_{\mathrm{fb}}$ is imposed, the solid level in the emitter bed (giving $\Delta \mathrm{P}_{\text {bed }}$ ) establishes at a value making $\Delta \mathrm{P}_{\text {drive }}$ high enough to compensate all energy losses generated by the solid flow in the tubes:

$\mathrm{P}_{\text {in }}=\Delta \mathrm{P}_{\text {bed }}+\mathrm{P}_{\mathrm{fb}}$,

$\Delta \mathrm{P}_{\text {drive }}=\Delta \mathrm{P}_{\text {bed }}+\mathrm{P}_{\mathrm{fb}}-\mathrm{P}_{\mathrm{atm}}$

Bed height variations lead to $\Delta \mathrm{P}_{\text {drive }}$ variations following $\Delta \mathrm{P}_{\text {bed }}$ variations. Since $\Delta \mathbf{P}_{\text {drive }}$ fluctuations may generate solid flow rate fluctuations in the tubes, the system stability needs low variations 


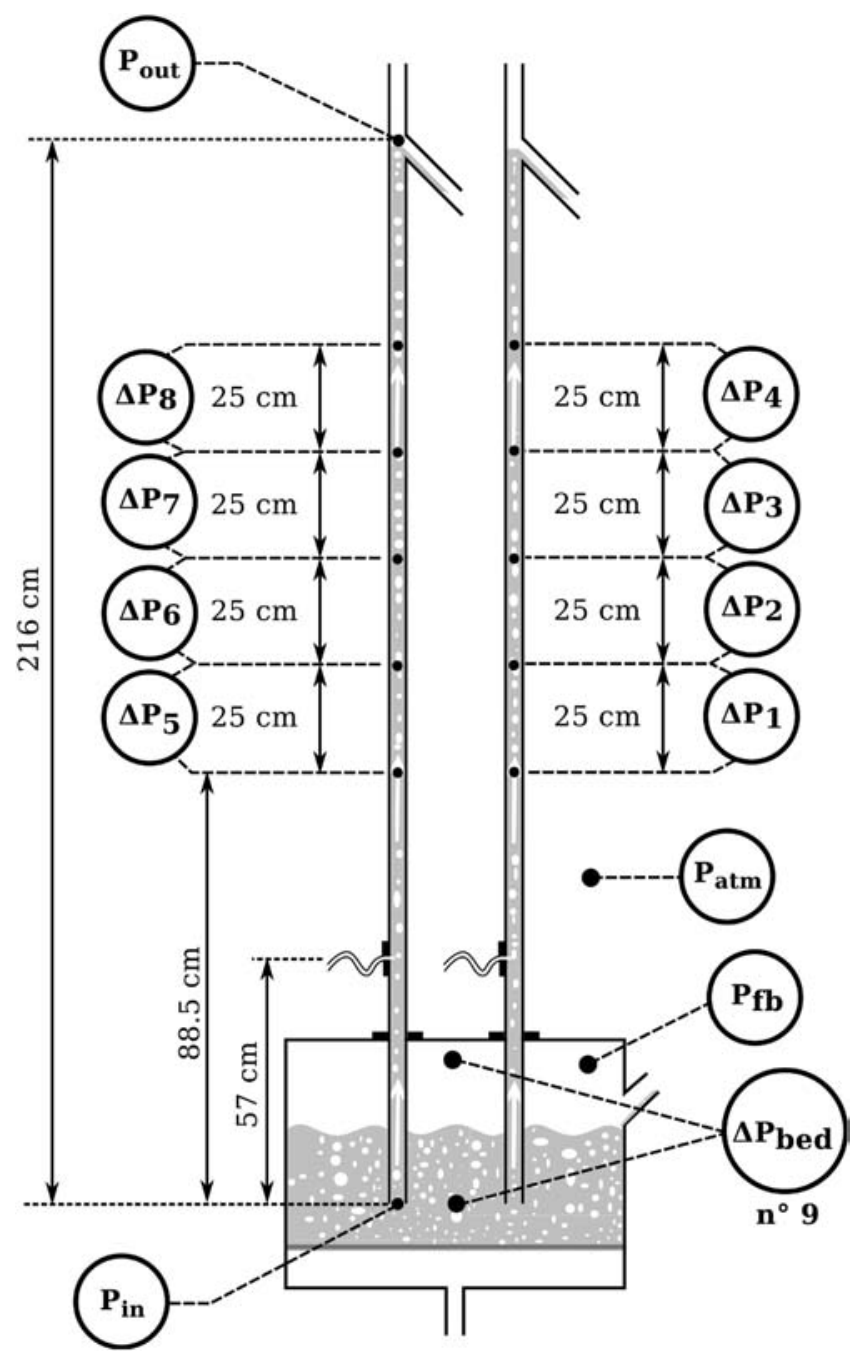

Figure 8. Sketch giving the tap positions of the pressure sensors.

of the bed height when the solid holdup varies. Therefore, the emitter bed surface has to be important enough to reduce its height variations with solid holdup variations. In this mock-up, a variation of $1 \mathrm{~kg}$ of solid holdup corresponds to approximately a $1 \mathrm{~cm}$ variation of bed height ( $\approx 1.3$ mbar of $\Delta \mathrm{P}_{\text {bed }}$ variation).

\section{STUDY OF THE OPERATING PARAMETERS}

The influence of 4 operating parameters on the suspension hydrodynamics and on the system stability is presented in this section:

- The fluidization gas flow rate of the emitter bed $\mathrm{Q}_{\mathrm{f}}$, that was varied between 1.75 and $4 \mathrm{Nm} \cdot \mathrm{h}^{-1}$ corresponding to $0.6 \mathrm{U}_{\mathrm{mb}}<\mathrm{U}_{\mathrm{f}}<1.4 \mathrm{U}_{\mathrm{mb}}$ (Air velocity in the emitter bed).

- The solid feeding flow rate of the emitter bed by the screw feeder $F_{p}$ that was varied between 20 and $130 \mathrm{~kg} \cdot \mathrm{h}^{-1}$.
- The aeration gas flow rate of conveying tubes that was varied between 0 and $240 \mathrm{NL} . \mathrm{h}^{-1}$ corresponding to $0<\mathrm{U}_{\mathrm{ae}}<8 \mathrm{U}_{\mathrm{mb}}$ (Superficial air velocity in the conveying tubes). Since the higher the aeration the lower the contact between the tube wall and the particles, when stability conditions were met, higher aeration was not investigated.

- The pressure of the emitter bed freeboard $\mathrm{P}_{\mathrm{fb}}$.

The operating parameters of the reference test case are reported in Table 2.

\section{Dynamic Behaviour of the System}

The system reactivity in front of perturbations is a very important concern. Indeed, for solar application, any incident solar flux increase must be followed by a quick increase of the solid flow rate in the tubes to avoid overheating. The system has also to stand air expansion due to it (hydrodynamic perturbations).

\section{Response to a solid feeding flow rate perturbation}

Figure 9 plots the transient bed hydrostatic pressure. Operating conditions are those of the reference case. At $t=0 \mathrm{~s}$, the solid feeding flow rate of the emitter bed is increased from $104 \mathrm{~kg} \cdot \mathrm{h}^{-1}$ to $130 \mathrm{~kg} . \mathrm{h}^{-1}$. The system only needs $250 \mathrm{~s}$ to reach its new steady state, and solid flow rate increases regularly during the transient regime.

The system reaches its new steady state without any external intervention. The solid level in the bed adapts itself (increase) to compensate the required increase of driving pressure. It is a selfcontrolled system.

\section{Response to an aeration flow rate perturbation}

In order to simulate a fast increase of solar radiation (fast increase/ decrease of incident radiation is the most often encountered variation in real operation of solar plants), the following test was performed: once at steady state of the reference test case, the aeration flow rate was increased by $20 \%$ (from $150 \mathrm{NL} . \mathrm{h}^{-1}$ to $180 \mathrm{NL} . \mathrm{h}^{-1}$ ). Figure 10 plots the hydrostatic pressure of the emitter bed versus time. During the transition regime, the bed hydrostatic pressure decreases, which means that the solid flow rate in the tubes increases. When the bed pressure reaches its new steady state, the sum of the instantaneous solid flow rates in the tubes is equal to the solid feeding flow rate $F_{p}=104 \mathrm{~kg} \cdot \mathrm{h}^{-1}$. Again, the solid level in the emitter bed decreased to compensate the tube hydrostatic pressure decrease (void fraction increase imposed by aeration increase). The system response time to this perturbation is about $250 \mathrm{~s}$.

\section{Solid Feeding Flow Rate Distribution Between the Tubes}

Another important concern is to put into evidence the even distribution of the solid in the tubes, which is very important in real solar operating conditions to have no overheating risk. Experiments were performed under operating conditions of the reference test case for 3 different solid feeding flow rates: 78, 104 and $130 \mathrm{~kg} \cdot \mathrm{h}^{-1}$. The solid was collected at both tube outlets in two separated vessels, during one hour-long steady state solid flow. The

Table 2. Operating parameters of the reference test case

\begin{tabular}{lcl}
\hline Fluidization flow rate $\left(\mathrm{Q}_{\mathrm{f}}\right)$ & Solid feeding flow rate $\left(\mathrm{F}_{\mathrm{p}}\right)$ & Aeration flow rate $\left(\mathrm{Q}_{\mathrm{ae}}\right)$ \\
\hline $\mathrm{Q}_{\mathrm{f}}=3.5 \mathrm{Nm}^{3} \cdot \mathrm{h}^{-1}$ & $104 \mathrm{~kg} \cdot \mathrm{h}^{-1}\left(52 \mathrm{~kg} \cdot \mathrm{h}^{-1}\right.$ per tube) & $150 \mathrm{NL}^{-1} \mathrm{~h}_{\mathrm{fb}}$ \\
$\mathrm{U}_{\mathrm{f}}=1.2 \mathrm{U}_{\mathrm{mb}}$ & & $\mathrm{U}_{\mathrm{ae}}=5 \mathrm{U}_{\mathrm{mb}}$ (tubes)
\end{tabular}




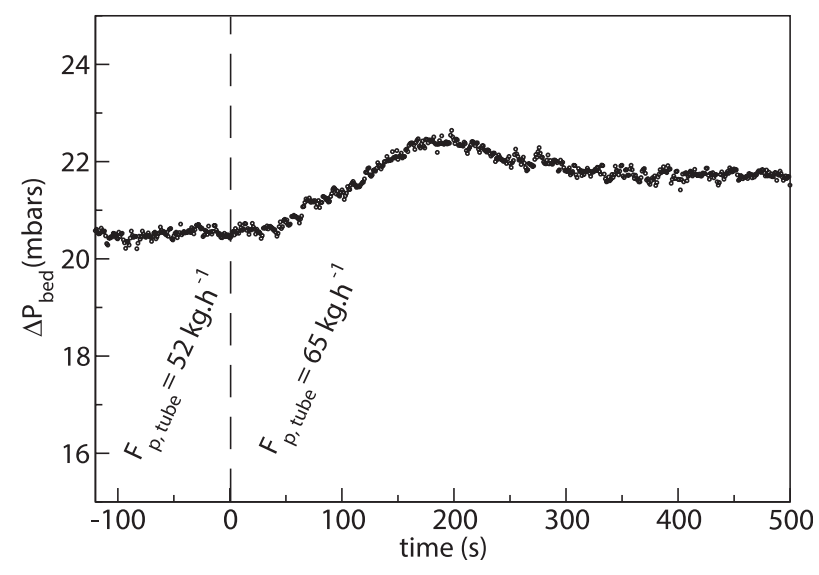

Figure 9. Response of the system to a solid feeding flow rate perturbation: when $\mathrm{t}<0 \mathrm{~s}, \mathrm{~F}_{\mathrm{p}}=104 \mathrm{~kg} \cdot \mathrm{h}^{-1}$ and when $\mathrm{t}>0 \mathrm{~s}, \mathrm{~F}_{\mathrm{p}}=130 \mathrm{~kg} \cdot \mathrm{h}^{-1}$.

distribution of the solid flow rates in the tubes is reported in Table 3.

Table 3 shows that for all solid feeding flow rates investigated, the solid flow rate is evenly distributed in the tubes.

In the following, the operating parameters are studied one by one. In each case, all parameters but the studied one are fixed at the reference test case values (see Table 2 ).

Influence of the Solid Feeding Flow Rate of the Emitter Bed

The solid flow rate influence was evaluated using the reference test case operating conditions $\left(\mathrm{Q}_{\mathrm{f}}=3.5 \mathrm{Nm}^{3} . \mathrm{h}^{-1}, \mathrm{Q}_{\mathrm{ae}}=150 \mathrm{NL} . \mathrm{h}^{-1}\right.$, $\mathrm{P}_{\mathrm{fb}}=248$ mbars) and by varying the solid feeding flow rate $F_{p}$ between $20 \mathrm{~kg} \cdot \mathrm{h}^{-1}$ and $130 \mathrm{~kg} \cdot \mathrm{h}^{-1}$.

Influence of the solid flow rate on the air flow rate exchanged between the bed and the tubes

The gas flow rate exchanged between the emitter bed and the tubes, named $Q_{b t}$ was evaluated using helium volume fraction measurements as presented in the section "Metrology". Figure 11 gives the time-averaged volume fraction of helium measured at the tubes' outlet during $30 \mathrm{~min}$ of steady regime as a function of the solid flow rate per tube $\left(\mathrm{F}_{\mathrm{p} \text {,tube }}\right)$.

Equation (2) gives $\mathrm{Q}_{\mathrm{bt}}$ as a function of $\mathrm{y}_{\mathrm{He}}$ and $\mathrm{Q}_{\mathrm{ae}}$. This flow rate expressed in [NL.h ${ }^{-1}$ ] is plotted in Figure 12 . $\mathrm{Q}_{\mathrm{bt}}$ increases linearly with $F_{p}$.

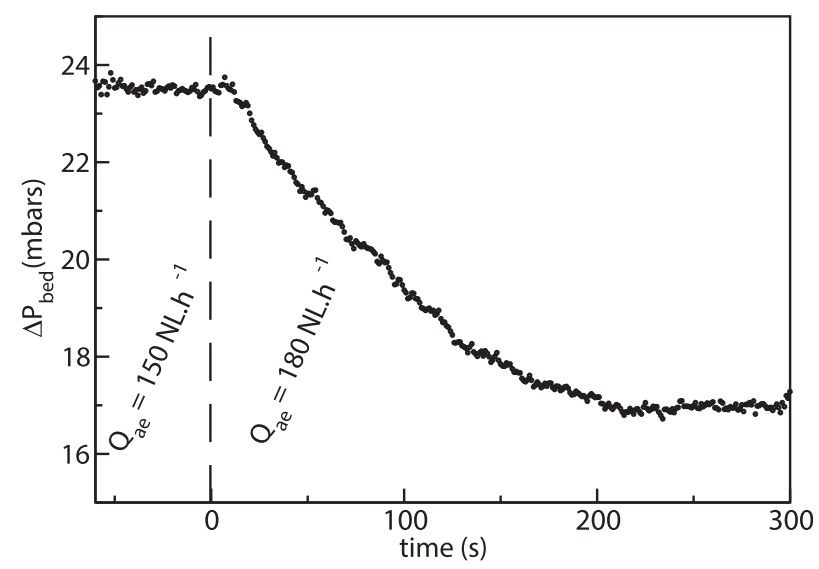

Figure 10. Response of the system to an aeration flow rate perturbation: when $\mathrm{t}<0 \mathrm{~s}, \mathrm{Q}_{\mathrm{ae}}=150 \mathrm{NL} \cdot \mathrm{h}^{-1}$ and when $\mathrm{t}>0 \mathrm{~s}, \mathrm{Q}_{\mathrm{ae}}=180 \mathrm{NL} \cdot \mathrm{h}^{-1}$.
Table 3. Distribution of solid flow rate between the two tubes: $\mathrm{Q}_{\mathrm{f}}=3.5 \mathrm{Nm}^{3} \cdot \mathrm{h}^{-1}, \mathrm{Q}_{\mathrm{ae}}=150 \mathrm{NL} \cdot \mathrm{h}^{-1}, \mathrm{P}_{\mathrm{fb}}=248 \mathrm{mbars}$

\begin{tabular}{lcc}
\hline $\begin{array}{l}\text { Solid feeding } \\
\text { flow rate } \\
\text { imposed by } \\
\text { the screwfeeder } \\
{\left[\mathrm{kg} \cdot \mathrm{h}^{-1}\right]}\end{array}$ & $\begin{array}{c}\text { Solid flow } \\
\text { rate in } \\
\text { the left side } \\
\text { tube } \\
{\left[\mathrm{kg} \cdot \mathrm{h}^{-1}\right]}\end{array}$ & $\begin{array}{c}\text { Solid flow } \\
\text { rate in } \\
\text { right side } \\
\text { tube } \\
{\left[\mathrm{kg} \cdot \mathrm{h}^{-1}\right]}\end{array}$ \\
\hline 78 & 37.4 & 38.1 \\
104 & 53.6 & 51.9 \\
130 & 65.5 & 67.4 \\
\hline
\end{tabular}

The linear fitting of the experimental data is

$\mathrm{Q}_{\mathrm{bt}}=12.55+0.66 \cdot \mathrm{F}_{\mathrm{p}, \text { tube }}$.

For a given fluidization flow rate, fluidization conditions remain the same at the tube inlet whatever the solid flow rate. In other words, the slip velocity between the gas and the particles does not change. In the same graph (Figure 12) the theoretical estimation of $\mathrm{Q}_{\mathrm{bt}}$ is plotted by considering the slip velocity between gas and particles at the minimum fluidization conditions and at the minimum bubbling conditions. This proves that the suspension at the tube inlet is under minimum fluidization conditions for any solid flow rate.

\section{Influence of the solid flow rate on the local void fraction}

Figure 13 plots the suspension local void fraction measured at four different heights on the tube above the aeration tap, for solid feeding flow rates in each tube ranging from 0 to $130 \mathrm{~kg} \cdot \mathrm{h}^{-1}$. As shown in Figure 13, under given fluidization and aeration flow rates, the solid flow rate in each tube has no influence on the suspension void fraction (all values at the same height are in the uncertainty domain). The void fraction increase with height is due to the gas expansion by decompression.

The difference between values at the same height is less than $1 \%$. The gas velocity at the tube inlet increases when the particle velocity increases, in order to keep the slip velocity equal to the minimum fluidization slip velocity. Consequently, the suspension void fraction keeps constant.

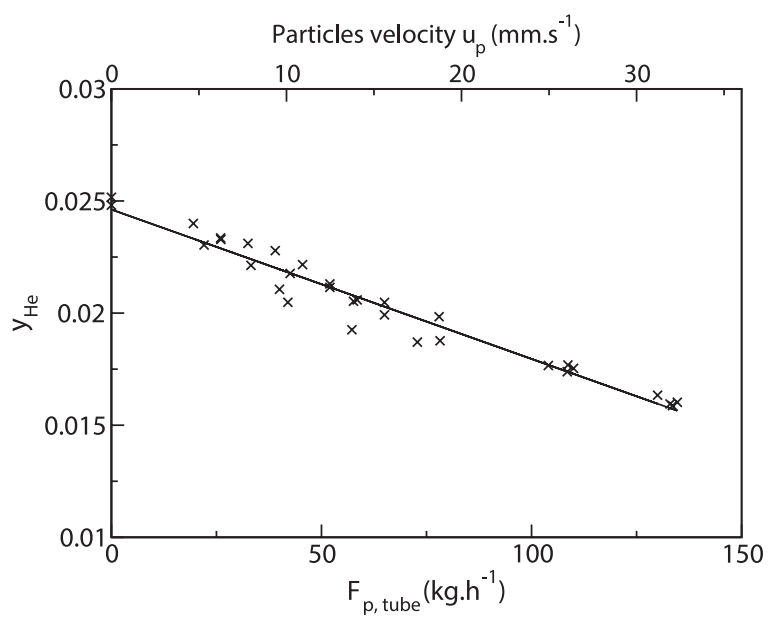

Figure 11. Effect of solid flow rate per tube on the helium volume fraction measured at the tube outlets: $\mathrm{Q}_{\mathrm{f}}=3.5 \mathrm{Nm}^{3} . \mathrm{h}^{-1}, \mathrm{Q}_{\mathrm{ae}}=150 \mathrm{NL} \cdot \mathrm{h}^{-1}$, $P_{\mathrm{fb}}=\mathrm{P}_{\mathrm{atm}}+248 \mathrm{mbars}$ and $0<\mathrm{F}_{\mathrm{p} \text {, tube }}<130 \mathrm{~kg} \cdot \mathrm{h}^{-1}$ ( $\mathrm{u}_{\mathrm{p}}$ is determined from the void fraction of Figure 23). 


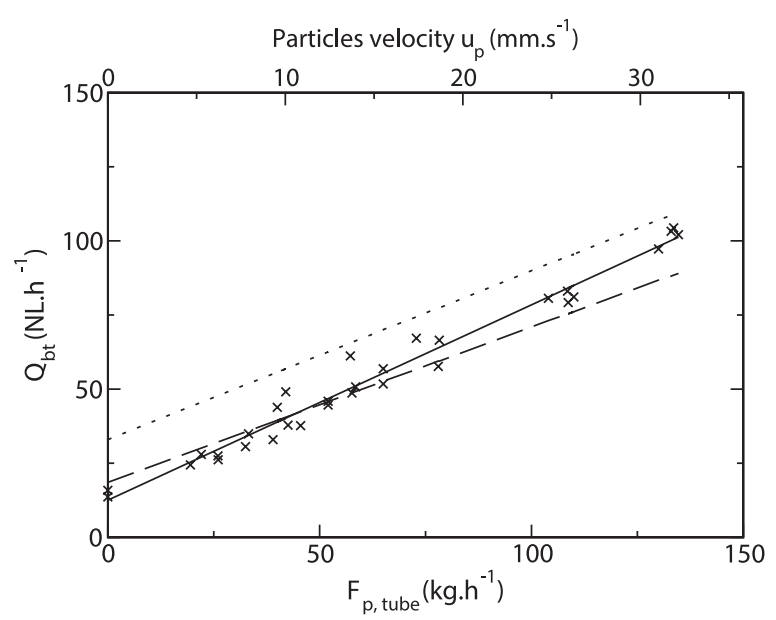

Figure 12. $\mathrm{Q}_{\mathrm{bt}}$ as a function of $\mathrm{F}_{\mathrm{p}}$, tube with $\mathrm{Q}_{\mathrm{f}}=3.5 \mathrm{Nm}^{3} \cdot \mathrm{h}^{-1}$, $\mathrm{Q}_{\mathrm{ae}}=150 \mathrm{NL} \cdot \mathrm{h}^{-1}, \mathrm{P}_{\mathrm{fb}}=\mathrm{P}_{\mathrm{atm}}+248 \mathrm{mbars}$ and $0<\mathrm{F}_{\mathrm{p}}$, tube $<130 \mathrm{~kg} \cdot \mathrm{h}^{-1}:(\mathrm{x})$ Experimental data, (-) fitted line, (---) gas mass flow rate calculated with minimum fluidization condition assumption at the inlet, (...) gas mass flow rate calculated with minimum bubbling condition assumption at the inlet ( $u_{p}$ determined from the void fraction of Figure 23).

\section{Influence of the solid flow rate on the driving pressure}

The solid flow rate also acts on the driving pressure of the flow, which corresponds to the total gas pressure drop required to ensure the imposed solid flow rate in the tubes. Equation (5) gives the driving pressure, which is the freeboard pressure, added to the bed hydrostatic pressure.

The driving pressure has to compensate for the hydrostatic pressure, the solid inertia increase and the wall-to-particles friction. For each tube, the hydrostatic pressure is the ratio of the solid mass in the tube over its cross section area. As the increase of solid inertia energy loss is negligible in front of both the wall-to-particle friction and the suspension hydrostatic pressure, it becomes:

$\Delta \mathrm{P}_{\text {drive }}=\Delta \mathrm{P}_{\text {hydro }}+\Delta \mathrm{P}_{\text {friction }}$.

Figure 14 plots the driving pressure measured as a function of the solid flow rate in each tube. Since the void fraction does not depend

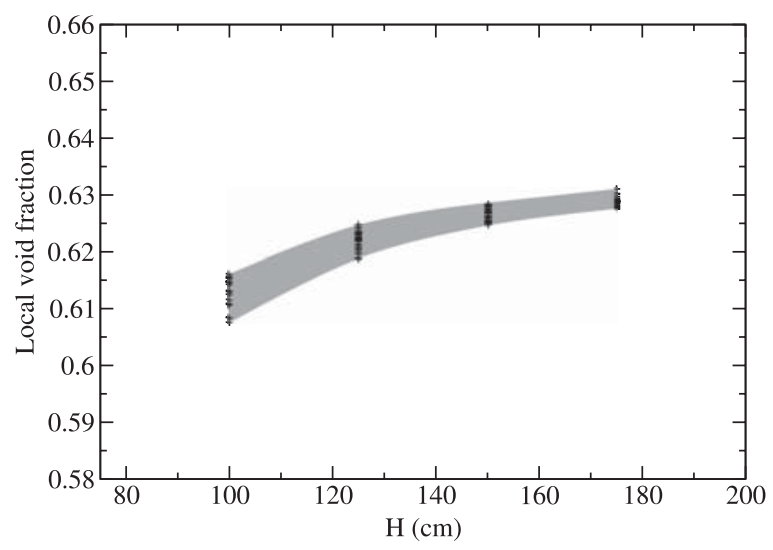

Figure 13. Effect of solid flow rate per tube on the local suspension void fraction at $100,125,150$ and $175 \mathrm{~cm}$ above the tube bottom: $\mathrm{Q}_{\mathrm{f}}=3.5 \mathrm{Nm}^{3} \cdot \mathrm{h}^{-1}, \mathrm{Q}_{\mathrm{ae}}=150 \mathrm{NL} \cdot \mathrm{h}^{-1}, \mathrm{P}_{\mathrm{fb}}=\mathrm{P}_{\mathrm{atm}}+248 \mathrm{mbars}$ and $0<\mathrm{F}_{\mathrm{p} \text {, tube }}<130 \mathrm{~kg} \cdot \mathrm{h}^{-1}$. on the solid flow rate (see subsection "Influence of the solid flow rate on the local void fraction"), the tube hydrostatic pressure is the same whatever the flow rate and corresponds to the driving pressure when the solid flow rate is zero. The intercept gives the hydrostatic pressure corresponding to the operating conditions $\mathrm{Q}_{\mathrm{f}}=3.5 \mathrm{Nm}^{3} \cdot \mathrm{h}^{-1}, \mathrm{Q}_{\mathrm{ae}}=150 \mathrm{NL} \cdot \mathrm{h}^{-1}$ and $\mathrm{P}_{\mathrm{fb}}=\mathrm{P}_{\mathrm{atm}}+248 \mathrm{mbars}$. Then, the slope of the graph gives directly the influence of the wall-to-particle friction to the gas pressure drop.

The linear fitting of the experimental data of Figure 14 gives

$\Delta \mathrm{P}_{\text {drive }}=266.63+0.04459 \cdot \mathrm{F}_{\mathrm{p}, \text { tube }}$.

It must be noticed that the wall-to-particles friction is strongly dependent on the tube material, which could lead to different results with metallic tubes instead of PVC tubes. It is also expected to be different at high temperature, because of the temperature influence on the particle surface properties.

\section{Influence of the Fluidization Flow Rate}

The fluidization flow rate influence on the system was studied using the reference test case operating conditions, by varying the fluidization flow rate of the emitter bed between $1.75 \mathrm{Nm}^{3} \cdot \mathrm{h}^{-1}$ and $4.25 \mathrm{Nm}^{3} . \mathrm{h}^{-1}\left(0.6 \mathrm{U}_{\mathrm{mb}}<\mathrm{U}_{\mathrm{f}}<1.4 \mathrm{U}_{\mathrm{mb}}\right.$ in the emitter bed).

The fluidization flow rate influence was observed through the solid flow distribution between the tubes and through the solid flow stability.

\section{Influence of the fluidization flow rate on the system symmetry}

Figure 15 displays the solid flow rate passing through the right side tube (obtained by direct collection at the tube outlet) as a function of the fluidization flow rate. The total solid flow rate $\left(104 \mathrm{~kg} \cdot \mathrm{h}^{-1}\right)$ is evenly distributed between the tubes when the fluidization velocity is over $U_{m b}$ (fluidization flow rate $3 \mathrm{Nm}^{3} \cdot h^{-1}$ ). Below this velocity, the solid preferably passes through one tube. This uneven distribution comes from the heterogeneous fluidization of the emitter bed when the gas velocity is below $U_{m b}$.

\section{Influence of the fluidization flow rate on the system stability}

The scope of the bed hydrostatic pressure is plotted as a function of the fluidization flow rate in Figure 16. It gives an estimation of the

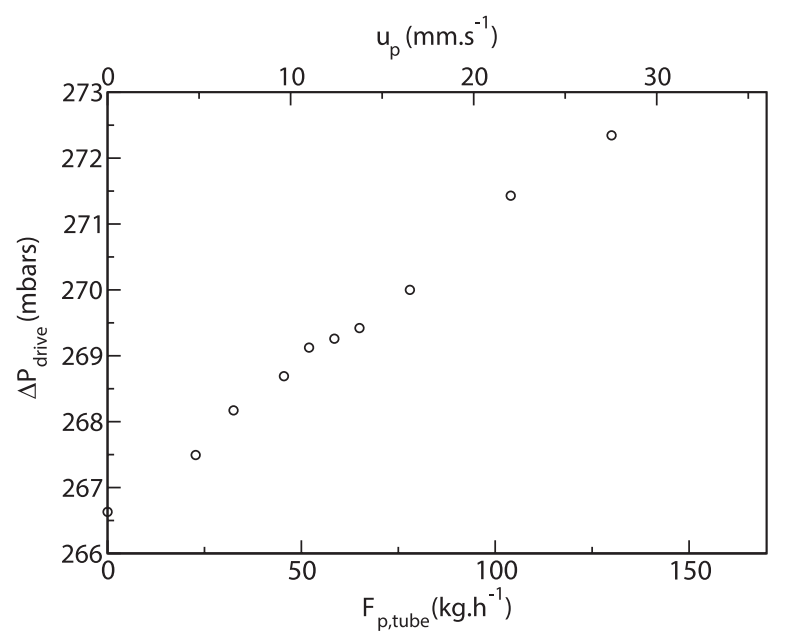

Figure 14. Effect of solid flow rate per tube on the driving pressure of the solid flow: $\mathrm{Q}_{\mathrm{f}}=3.5 \mathrm{Nm}^{3} \cdot \mathrm{h}^{-1}, \mathrm{Q}_{\mathrm{ae}}=150 \mathrm{NL} \cdot \mathrm{h}^{-1}, \mathrm{P}_{\mathrm{fb}}=\mathrm{P}_{\mathrm{atm}}+248$ mbars and $0<F_{p}$, tube $<130 \mathrm{~kg} \cdot \mathrm{h}^{-1}$ ( $\mathrm{u}_{\mathrm{p}}$ is determined from the void fraction of Figure 23). 


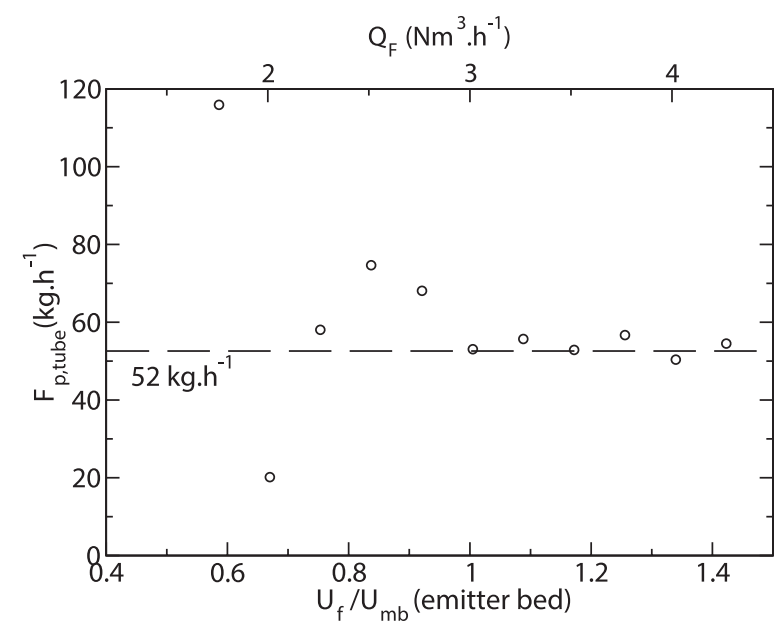

Figure 15. Solid flow in the right side tube as a function of the fluidization flow rate: $F_{p}=104 \mathrm{~kg} \cdot \mathrm{h}^{-1}, \mathrm{Q}_{\mathrm{ae}}=150 \mathrm{NL} \cdot \mathrm{h}^{-1}, \mathrm{P}_{\mathrm{fb}}=\mathrm{P}_{\mathrm{atm}}+248 \mathrm{mbars}$ and $1.75<\mathrm{Q}_{\mathrm{ae}}<4.25 \mathrm{Nm}^{3} . \mathrm{h}^{-1}$.

flow stability in the tube. It corresponds to a maximum change in the bed mass at steady state. With this bed geometry, a scope of 1.5 mbars corresponds to a maximum of mass variation of about $1.14 \mathrm{~kg}$ ( $1.1 \%$ of the solid feeding flow rate).

The solid flow stability in the vertical tubes is greatly influenced by the fluidization flow rate of the emitter bed, and the conclusion is almost the same: the fluidization velocity must be higher than the minimum bubbling velocity to ensure an acceptable stability because at low gas velocity the bed is heterogeneously fluidized.

Then, for higher velocities, the solid flow stability in the tubes is not improved.

In these two previous results, the optimal fluidization velocity ranges between 1 and $1.4 \mathrm{U}_{\mathrm{mb}}$. Therefore, the reference value was chosen as $1.2 \mathrm{U}_{\mathrm{mb}}$.

\section{Influence of the Aeration Flow Rate}

Aeration jets are lateral injections of air at $0.57 \mathrm{~m}$ above the tube bottom. They act on the suspension void fraction by increasing the gas velocity in the tubes. Experiments were run under the reference test case operating conditions $\left(\mathrm{F}_{\mathrm{p}}=104 \mathrm{~kg} \cdot \mathrm{h}^{-1}, \mathrm{Q}_{\mathrm{f}}=3.5 \mathrm{Nm}^{3} \cdot \mathrm{h}^{-1}\right.$ $\left(\approx 1.2 \mathrm{U}_{\mathrm{mb}}\right)$ ) and by varying the aeration flow rate in the range 0 to

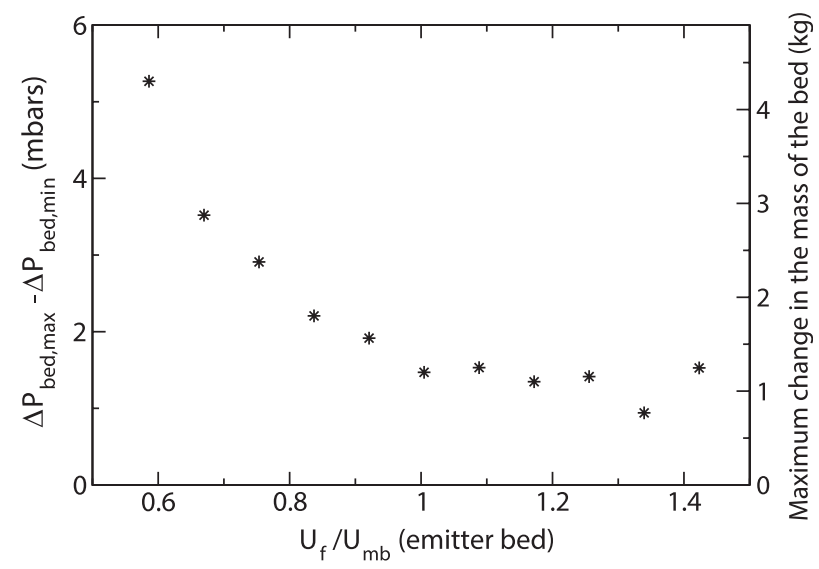

Figure 16. Scope of the bed pressure as a function of the fluidization flow rate: $\mathrm{F}_{\mathrm{p}}=3.5 \mathrm{~kg} \cdot \mathrm{h}^{-1}, \mathrm{Q}_{\mathrm{ae}}=150 \mathrm{NL} \cdot \mathrm{h}^{-1}, \mathrm{P}_{\mathrm{fb}}=\mathrm{P}_{\mathrm{atm}}+248 \mathrm{mbars}$ and $1.75<\mathrm{Q}_{\mathrm{f}}<4.25 \mathrm{Nm}^{3} \cdot \mathrm{h}^{-1}$.
240 NL. $\mathrm{h}^{-1}$. This range corresponds to a gas velocity ranging between 0 and $7.3 \mathrm{U}_{\mathrm{mb}}$ referred to the tube cross-section area.

\section{Influence of the aeration flow rate on the solid flow stability}

The aeration flow rate has mainly an impact on the solid flow stability in the vertical tubes. Figures $17-20$ give the transient emitter bed solid holdup evolution during experiments run at 4 different aeration flow rates. Fluctuations decrease with the aeration flow rate. The solid holdup increases first because of the transitional period, before the bed level reaches its new steady state value.

Figure 21 plots both the emitter bed hydrostatic pressure scope on the steady state regime and the corresponding maximum solid holdup variation as a function of the aeration flow rate. The solid holdup does not fluctuate for aerations over $150 \mathrm{NL} \cdot \mathrm{h}^{-1}$. It is concluded that aerations of at least $150 \mathrm{NL} . \mathrm{h}^{-1}$ are required to ensure good solid flow stability.

\section{Influence of the aeration flow rate on the driving pressure}

The aeration flow rate greatly impacts the driving pressure for given solid and fluidization flow rates. Figure 22 plots the driving pressure versus the aeration flow rate. When the aeration flow rate increases from 0 to $240 \mathrm{NL} . \mathrm{h}^{-1}$, the driving pressure decreases from 295 mbars to 255 mbars ( $14 \%$ decrease).

This decrease is due to the aeration effect on the suspension void fraction. The void fraction plotted in Figure 23 is determined by considering that the solid mass in each tube is responsible of the hydrostatic pressure on the tube (Equation (9)). As explained in the subsection "Influence of the solid flow rate on the driving pressure", the measured driving pressure is considered to be the sum of the pressure drop by wall-to-particles friction and the hydrostatic pressure drop on the tube due to the solid weight (Equation (7)). The assumption was made that for a given solid flow rate, the void fraction has no effect on the pressure drop by wall-to-particle friction in our reduced range of void fraction variation. Consequently, in order to determine the void fraction in the tube, the pressure drop by friction (Figure 14) was taken away to isolate the hydrostatic pressure from the measured driving pressure given Equation (5)

$\varepsilon=1-\frac{\Delta P_{h y d r o}}{\rho_{p} \cdot g \cdot L_{C}}$

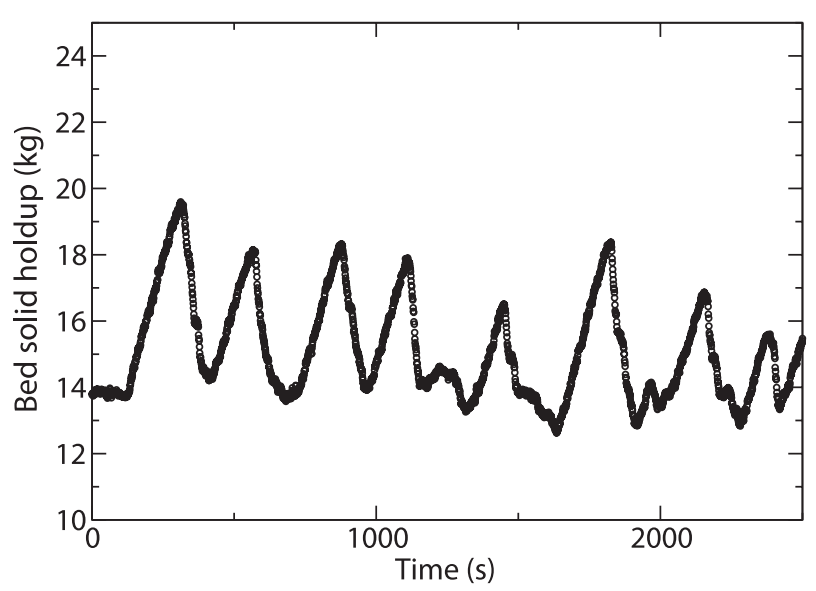

Figure 17. Solid holdup of the emitter bed as a function of time with $Q_{a e}=0 N L \cdot h^{-1}\left(Q_{f}=3.5 \mathrm{Nm}^{3} \cdot h^{-1}, F_{p}=104 \mathrm{~kg} \cdot \mathrm{h}^{-1}\right)$. 


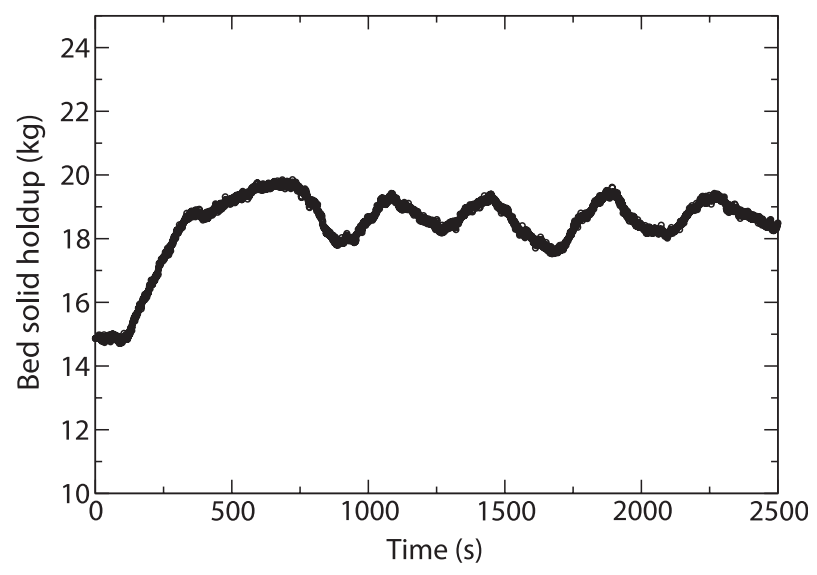

Figure 18. Solid holdup of the emitter bed as a function of time with $\mathrm{Q}_{\mathrm{ae}}=40 \mathrm{NL} \cdot \mathrm{h}^{-1}\left(\mathrm{Q}_{\mathrm{f}}=3.5 \mathrm{Nm}^{3} \cdot \mathrm{h}^{-1}, \mathrm{~F}_{\mathrm{p}}=104 \mathrm{~kg} \cdot \mathrm{h}^{-1}\right)$.

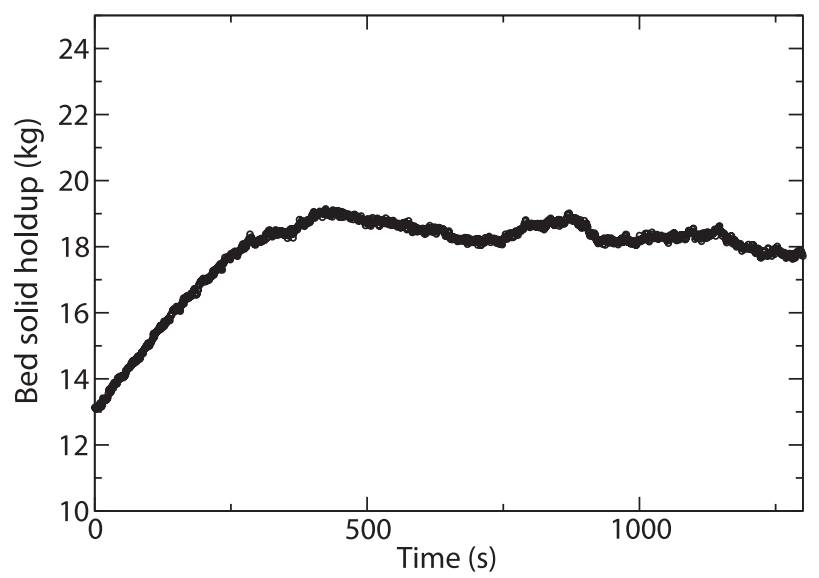

Figure 19. Solid holdup of the emitter bed as a function of time with $\mathrm{Q}_{\mathrm{ae}}=80 \mathrm{NL} \cdot \mathrm{h}^{-1}\left(\mathrm{Q}_{\mathrm{f}}=3.5 \mathrm{Nm}^{3} \cdot \mathrm{h}^{-1}, \mathrm{~F}_{\mathrm{p}}=104 \mathrm{~kg} \cdot \mathrm{h}^{-1}\right)$.

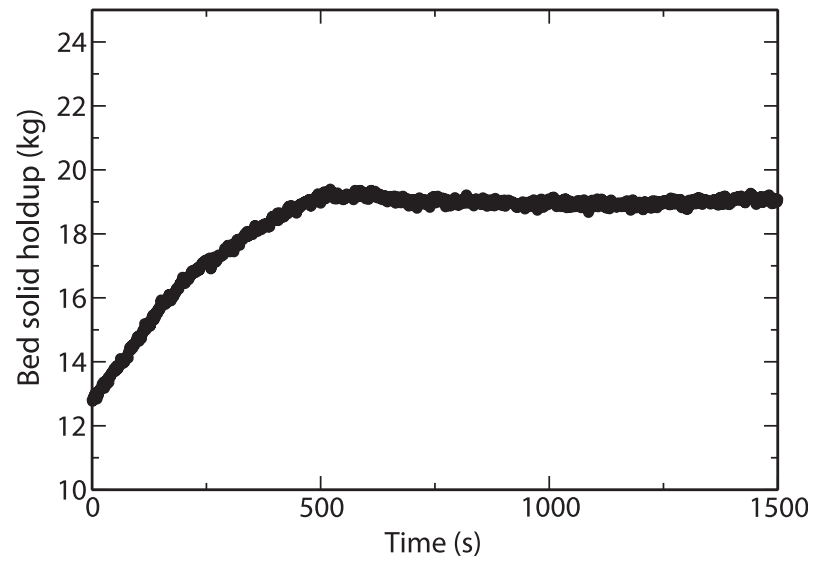

Figure 20. Solid holdup of the emitter bed as a function of time with $\mathrm{Q}_{\mathrm{ae}}=180 \mathrm{NL} \cdot \mathrm{h}^{-1}\left(\mathrm{Q}_{\mathrm{f}}=3.5 \mathrm{Nm}^{3} \cdot \mathrm{h}^{-1}, \mathrm{~F}_{\mathrm{p}}=104 \mathrm{~kg} \cdot \mathrm{h}^{-1}\right)$.

The linear fitting of the void fraction versus the aeration flow rate at $52 \mathrm{~kg} \cdot \mathrm{h}^{-1}$ of solid flow rate (reference value) is

$\varepsilon=0.57+0.000249 \cdot Q_{a e}$.

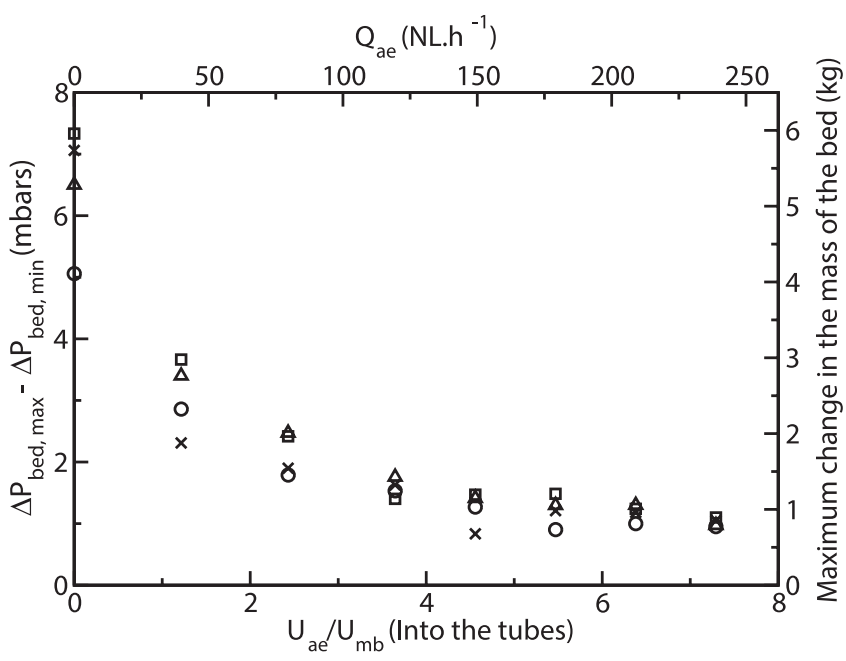

Figure 21. Effect of aeration flow rate on the hydrostatic pressure scope of the emitter bed for 4 different solid flow rates per tube: (o) $39 \mathrm{~kg} \cdot \mathrm{h}^{-1},(\square)$ $52 \mathrm{~kg} \cdot \mathrm{h}^{-1},(\mathrm{x}) 65 \mathrm{~kg} \cdot \mathrm{h}^{-1},(\Delta) 80 \mathrm{~kg} \cdot \mathrm{h}^{-1}\left(\mathrm{Q}_{\mathrm{f}}=3.5 \mathrm{Nm}^{3} \cdot \mathrm{h}^{-1}\right)$.

\section{Influence of the aeration flow rate on the local void fraction}

The aeration flow rate influence on the local void fraction can be evaluated above the aeration tap. Figure 24 gives the local void fraction deduced from the local pressure drop along the pipe (pressure sensors $\mathrm{n}^{\circ} 1$ to 8 ). Void fraction is then calculated by Equation (9).

The void fraction in the tube increases with the aeration flow rate. At a given aeration flow rate, the void fraction increases with the height because the gas expands when the pressure decreases.

An important remark: the suspension void fraction increase with aeration makes necessary the decrease of the freeboard pressure to keep the solid level in the emitter bed over the tube bottoms. Indeed, the driving pressure equals the sum of the freeboard pressure and of the emitter bed hydrostatic pressure (imposed by the bed height from the tube bottom to the emitter bed surface). If the freeboard pressure does not decrease with the aeration flow rate, the emitter bed surface would lower down to the tube bottoms, and therefore the tubes would not keep immerged in the bed.

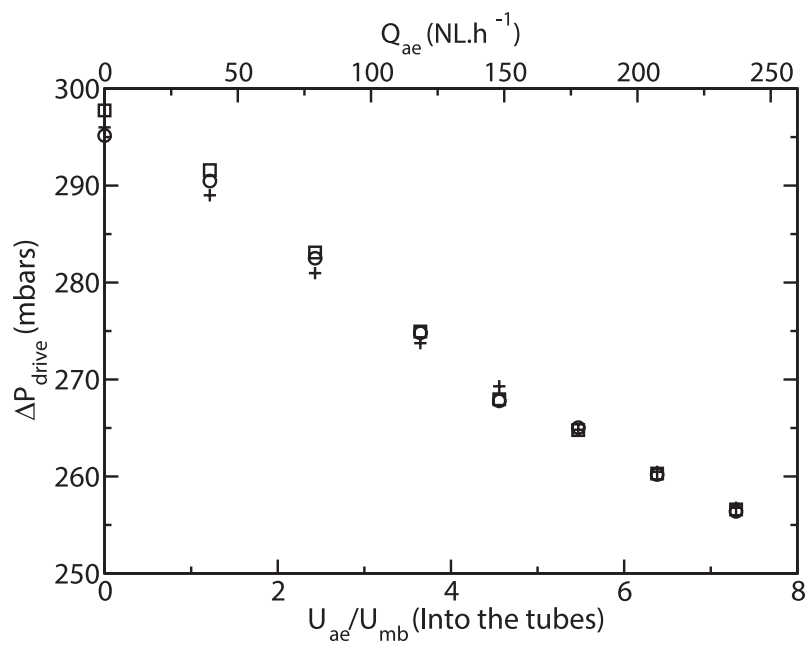

Figure 22. Effect of aeration flow rate on the driving pressure of the emitter bed for 3 different solid flow rates per tube: (o) $52 \mathrm{~kg} \cdot \mathrm{h}^{-1},(\square) 65 \mathrm{~kg} \cdot \mathrm{h}^{-1},(+)$ $80 \mathrm{~kg} \cdot \mathrm{h}^{-1}\left(\mathrm{Q}_{\mathrm{f}}=3.5 \mathrm{Nm}^{3} \cdot \mathrm{h}^{-1}\right)$. 


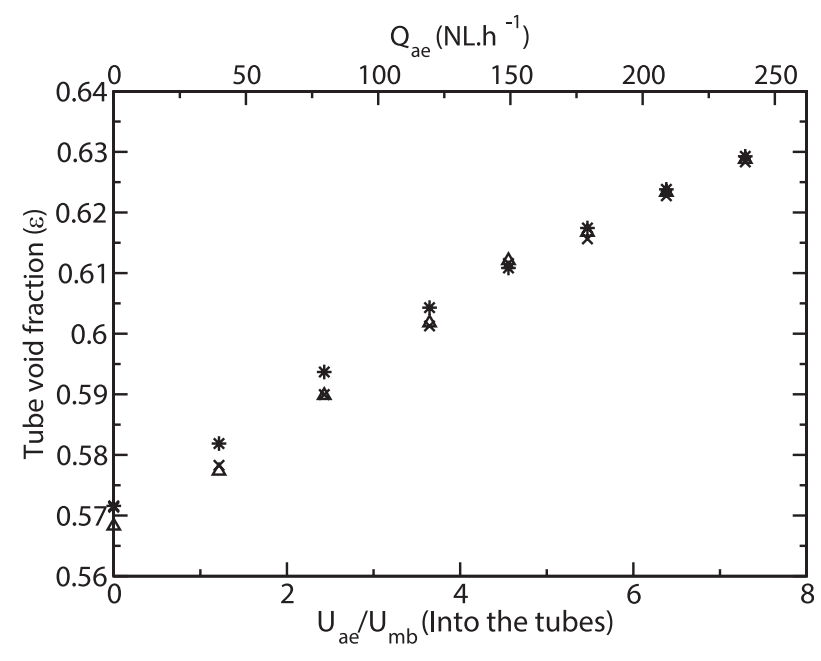

Figure 23. Effect of aeration flow rate on the overall tube void fraction for 3 different solid flow rates per tube: (x) $52 \mathrm{~kg} \cdot \mathrm{h}^{-1},(\Delta) 65 \mathrm{~kg} \cdot \mathrm{h}^{-1},(\star) 80 \mathrm{~kg}$. $\mathrm{h}^{-1}\left(\mathrm{Q}_{\mathrm{f}}=3.5 \mathrm{Nm}^{3} \cdot \mathrm{h}^{-1}\right)$.

\section{Influence of Freeboard Pressure}

The freeboard pressure has only one effect on the system. Under reference operating conditions of the parameters, if the freeboard pressure is slightly increased from 248 mbars to 250 mbars (for example), it induces a 2 mbars decrease of the hydrostatic bed pressure in order to keep constant the driving pressure, which is the sum of the freeboard pressure and of the hydrostatic bed pressure. Table 4 shows clearly that any increase/decrease of the freeboard pressure results in the same decrease/increase of the hydrostatic bed height in order to conserve the driving pressure.

Sensitivity of the System Facing an Aeration Imbalance Between the Tubes

In order to estimate the sensitivity of the system in front of an aeration flow rate imbalance between the tubes, aeration flow rates were intentionally de-equilibrated starting from the reference test case operating conditions. The solid flow rate distribution was measured by collecting the solid at both tube outlets. The results are given in Table 5 .

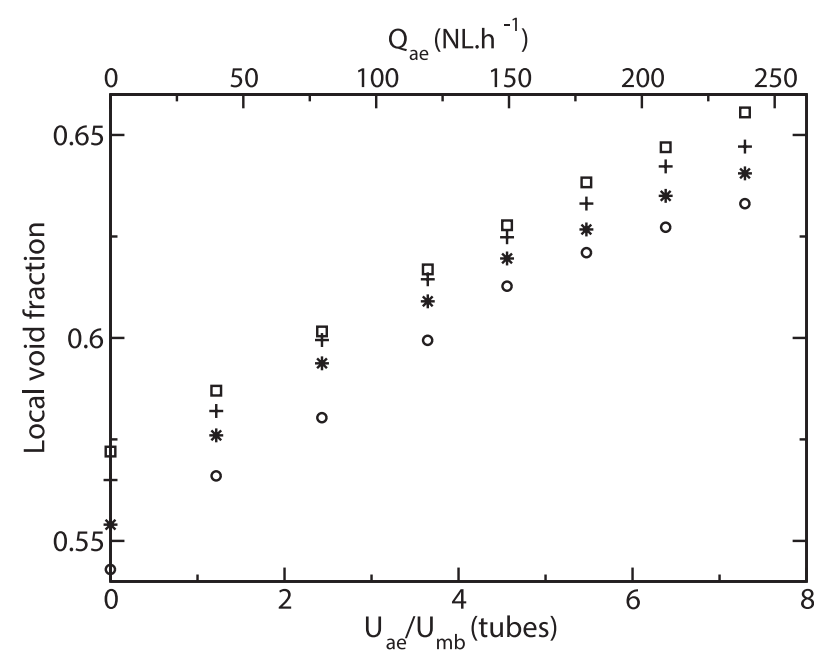

Figure 24. Effect of aeration flow rate on the local void fraction at different heights above the tube bottom: $(\circ) 100 \mathrm{~cm},(\star) 125 \mathrm{~cm},(+) 150 \mathrm{~cm}$ and (口) $175 \mathrm{~cm}$ with $\mathrm{F}_{\mathrm{p}}=104 \mathrm{~kg} \cdot \mathrm{h}^{-1}$ and $\mathrm{Q}_{\mathrm{f}}=3.5 \mathrm{Nm}^{3} \cdot \mathrm{h}^{-1}$.
Table 4. Effect of freeboard pressure on the system with the following operating parameters: $F_{p}=104 \mathrm{~kg} \cdot \mathrm{h}^{-1}, \mathrm{Q}_{\mathrm{ae}}=120 \mathrm{NL} \cdot \mathrm{h}^{-1}, \mathrm{Q}_{\mathrm{f}}=3 \mathrm{Nm}^{3}$. $\mathrm{h}^{-1}$ and for 3 different freeboard pressures $(252,255$ and $258 \mathrm{mbars})$

\begin{tabular}{llll}
\hline Freeboard pressure [mbars] & 251.57 & 254.56 & 257.52 \\
Hydrostatic bed pressure [mbars] & 22.48 & 19.51 & 16.56 \\
Driving pressure [mbars] & 274.05 & 274.07 & 274.08
\end{tabular}

Table 5 clearly demonstrates that the solid flow rate distribution between the tubes depends on the aeration flow rate difference between the tubes. When the aeration imbalance is over $24 \mathrm{NL} . \mathrm{h}^{-1}$, all solid particles go through the more aerated tube. Indeed, in the more aerated tube, the hydrostatic pressure of the suspension added to the wall-to-particles friction pressure drop is lower than the hydrostatic pressure of the less aerated tube. This explains why the solid only circulates then through the more aerated tube. This situation is totally proscribed in real solar conditions.

\section{MODELLING OF GAS-PARTICLE SUSPENSION UPWARD FLOW}

The suspension flow generated in the presented mock-up is pressure-driven, but in the covered range of gas and solid mass fluxes, the solid entrainment by bubble wake must be considered, as it was proved by Rowe and Partridge with X-ray study. ${ }^{[21]}$ Thus, the description of the suspension flow is based on the bubbleemulsion model formalism, and considers the solid entrainment by the bubble wake. The suspension behaviour is not equivalent to that of a fluidized bed as the tube diameter is small and as the cross section averaged particle velocity is positive. The tube geometry is considered in the correlations that give the bubble size and velocity.

\section{Assumptions, Equations and Correlations of the Model}

The developed model may be considered as the classical bubbleemulsion model to which are added

- the gas phase compressibility;

- the vertical upward movement of particles;

- the variation of emulsion void fraction with the emulsion slip velocity.

The basic principle of this approach is to consider each elementary volume as a set of three phases (Figure 25):

- An emulsion phase (composed of gas and particles).

- A bubble phase (only composed of gas).

- A wake phase (composed of gas and particles), having the same void fraction than the emulsion phase and the same velocity than bubbles.

At the inlet, the assumption of a slip velocity between the gas and the particles corresponding to the minimum fluidization conditions was selected and validated by helium concentration measurements (Figure 12). The inlet pressure of the tube is determined by successive iterations until the outlet pressure equals the atmospheric pressure. The model equations at steady state are reported in Table 6 . The properties of bubbles (diameter, velocity) are taken from literature. Equations are discretized and solved by the Newton's algorithm.

\section{Model Predictions and Comparison with Experimental Results}

Figure 26 compares the driving pressure model predictions with the experimental data as a function of the aeration flow rate. The driving pressure seems to be well predicted by the implemented model. 
Table 5. Sensitivity of the system facing unequal aeration flow rate between the tubes with the following operating parameters: $F_{p}=104 \mathrm{~kg} \cdot \mathrm{h}^{-1}$, $\mathrm{Q}_{\mathrm{f}}=3 \mathrm{Nm}^{3} \cdot \mathrm{h}^{-1}$ and $\mathrm{P}_{\mathrm{fb}}=248$ mbars

\begin{tabular}{|c|c|c|c|c|c|c|c|c|c|}
\hline Test $\mathrm{N}^{\circ}$ & 1 & 2 & 3 & 4 & 5 & 6 & 7 & 8 & 9 \\
\hline $\mathrm{Q}_{\mathrm{ae}, \text { right }}\left[\mathrm{NL} \cdot \mathrm{h}^{-1}\right]$ & 150 & 150 & 150 & 150 & 150 & 150 & 150 & 150 & 150 \\
\hline $\mathrm{Q}_{\mathrm{ae}, \text { left }}\left[\mathrm{NL} \cdot \mathrm{h}^{-1}\right]$ & 150 & 147 & 144 & 141 & 138 & 135 & 132 & 129 & 126 \\
\hline $\mathrm{F}_{\mathrm{p} \text {, right }}\left[\mathrm{kg} \cdot \mathrm{h}^{-1}\right]$ & 52.3 & 58.8 & 64.5 & 71.0 & 77.5 & 84.8 & 91.1 & 98.3 & 103.8 \\
\hline$F_{p}$, left $\left[k g \cdot h^{-1}\right]$ & 52.3 & 47.4 & 40.0 & 33.2 & 26.2 & 19.6 & 13.8 & 5.8 & 0.3 \\
\hline $\mathrm{F}_{\mathrm{p}, \text { tot }}\left[\mathrm{kg} \cdot \mathrm{h}^{-1}\right]$ & 104.6 & 106.2 & 104.5 & 104.2 & 103.7 & 104.4 & 104.9 & 104.1 & 104.1 \\
\hline$\Delta \mathrm{P}_{\text {drive }}[\mathrm{mbars}]$ & 268.9 & 269.15 & 269.3 & 269.5 & 269.7 & 269.95 & 270.3 & 270.55 & 270.8 \\
\hline
\end{tabular}
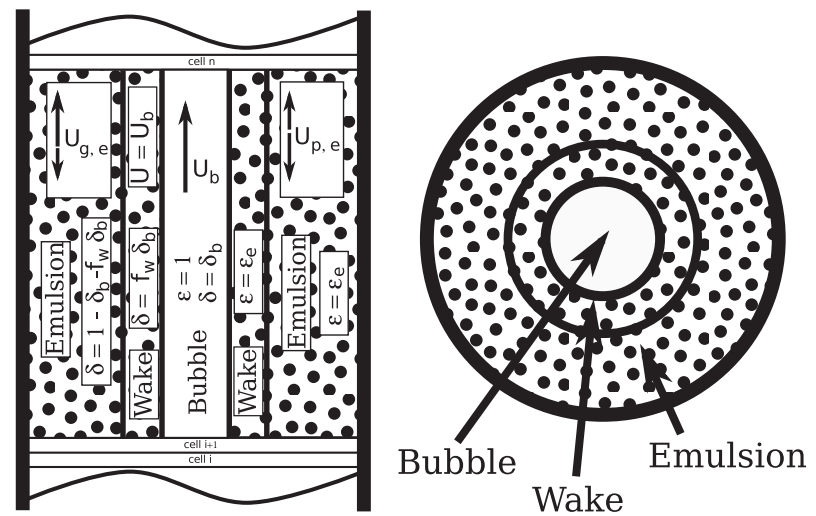

Figure 25. Schematic view of the model formalism.

Figure 27 compares the model prediction of axial pressure profiles by both considering and neglecting the gas compressibility. It appears that the gas compressibility must be considered to fit the experimental axial pressure profile along the pipe.

\section{CONCLUSIONS AND FUTURE WORK}

Research developments on HTFs for high-concentration solar plants are justified by the drawbacks of existing HTF: limited range of working temperature, corrosiveness, and energy consumption by pumping. Flamant and Hemati proposed in this aim the use of dense gas-particle suspensions directly as heat transfer and storage fluid to solar energy application. It consists in creating a gas-solid dense suspension upward flow, in a vertical bundle of small diameter tubes constituting the solar receiver, which have their bottom immerged in a slightly pressurized fluidized bed. The suspension void fraction in the tube is closed to that of a dense fluidized bed. This type of solid flow is yet implemented in the field of hyper-dense phase vertical conveying of powders and it is currently under development for solar receivers with the financial support of the European Commission. The main technological challenge about this new type of exchanger was to control the solid flow and its even distribution in the tubes (accuracy, stability and regime).

A cold lab-scale mock-up was built in the laboratory premises. This mock-up is composed of two $34 \mathrm{~mm}$ i.d. vertical tubes with their bottom end immerged in a fluidized bed (emitter fluid bed), solid fed from a hopper. Its processing confirmed the ability to ensure the upward flow of concentrated gas-solid suspensions into a bundle of tubes in parallel. The operating parameters tested were the fluidization flow rate of the emitter bed, the aeration flow rate of the tubes and the solid flow rate imposed by the screw-feeder. The fluidization flow rate of the emitter bed was varied between 1.75 and $4.25 \mathrm{Nm}^{3} \cdot \mathrm{h}^{-1}$ ( 0.6 to $1.4 \mathrm{U}_{\mathrm{mb}}$ in the emitter bed). For fluidization velocities of the emitter bed higher than the minimum bubbling velocity, there is no effect on the hydrodynamic behaviour of the suspension in the tubes. The aeration flow rate of the tubes was varied between 0 and $240 \mathrm{NL} . \mathrm{h}^{-1}\left(0\right.$ to $7.5 \mathrm{U}_{\mathrm{mb}}$ in the tubes). The aeration flow rate increases the suspension void fraction in the tubes, thus decreasing the driving pressure needed to the suspension flow ( $14 \%$ decrease on the covered range of aeration flow rate). The solid flow rate imposed by the screw-feeder was varied between 20 and $130 \mathrm{~kg} \cdot \mathrm{h}^{-1}$. Helium tracing of the gas phase demonstrated that the gas flow rate that comes from the emitter bed and that flows through the tubes increases with solid flow rate. The gas pressure losses from wall-to-particle friction also increase with solid flow rate.

Operating conditions for stable suspension upward flows and even distribution of the total solid flow rate between the tubes were

Table 6. Equations of the model

\begin{tabular}{|c|c|}
\hline Gas local mass balance & $\frac{d F_{g}}{d z}=Q_{a e}$, where $Q_{a e}$ represents a gas source term (air injections) \\
\hline Gas mass flow rate & $\begin{array}{l}F_{g}=\rho_{g} \cdot A_{c} \cdot\left(1-\delta_{b}-f_{w} \cdot \delta_{b}\right) \cdot \varepsilon_{e} \cdot u_{g, e} \\
+\rho_{g} \cdot A_{c} \cdot f_{w} \cdot \varepsilon_{e} \cdot U_{b}+\rho_{g} \cdot A_{c} \cdot f_{w} \cdot \delta_{b} \cdot U_{b}\end{array}$ \\
\hline Void fraction & $\varepsilon_{g}=\left(1-\delta_{b}-f_{w} \cdot \delta_{b}\right) \cdot \varepsilon_{e}+f_{w} \cdot \delta_{b} \cdot \varepsilon_{e} \cdot+\delta_{b}=\left(1-\delta_{b}\right) \cdot \varepsilon_{e}+\delta_{b}$ \\
\hline Solid local mass balance & $\frac{d F_{p}}{d z}=0$ \\
\hline Solid mass flow rate & $\begin{array}{l}F_{p}=\rho_{p} \cdot A_{c} \cdot\left(1-\delta_{b}-f_{w} \cdot \delta_{b}\right) \cdot\left(1-\varepsilon_{e}\right) \cdot u_{p, e} \\
+\rho_{p} \cdot A_{c} \cdot f_{w} \cdot \delta_{b} \cdot\left(1-\varepsilon_{e}\right) \cdot U_{b}+\rho_{g} \cdot A_{c} \cdot f_{w} \cdot \delta_{b} \cdot U_{b}\end{array}$ \\
\hline Solid void fraction & $\varepsilon_{p}=\left(1-\varepsilon_{e}\right) \cdot f_{w} \cdot \delta_{b}+\left(1-\varepsilon_{e}\right) \cdot\left(1-\delta_{b}-f_{w} \cdot \delta_{b}\right)$ \\
\hline Continuity equation & $\varepsilon_{g}+\varepsilon_{p}=1$ \\
\hline Gas pressure & $\frac{d P}{d z}=-\left(1-\varepsilon_{g}\right) \cdot \rho_{p} \cdot g$, simplification of momentum equations \\
\hline Bubble velocity (Davidson and Harrison) ${ }^{[23]}$ & $U_{b}=U_{g}-U_{m f}+0.711 \cdot \sqrt{g \cdot d_{b}+U_{b}}$ \\
\hline Diameter of bubbles (Mori and Wen) ${ }^{[24]}$ & $d_{b}=d_{b m}-\left(d_{b m}-d_{b 0}\right) \cdot \exp \left(-0.3 \cdot \frac{z}{D_{c}}\right)$, with $d_{b m}=0.64 \cdot\left(A_{c} \cdot\left(U_{g}-U_{m f}\right)\right)^{0.4}$ \\
\hline Wake fraction & $f_{w}=0.3$ \\
\hline
\end{tabular}




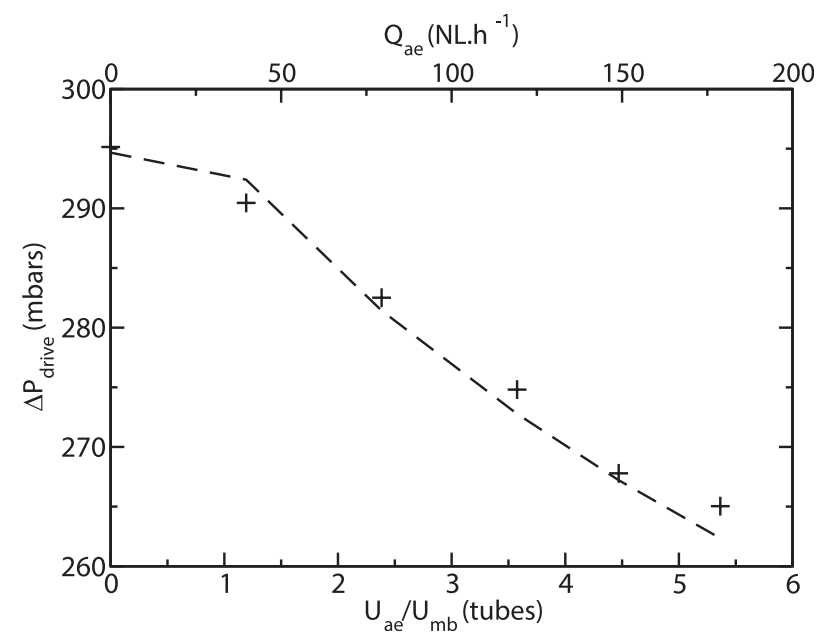

Figure 26. Comparison between 1D bubble-emulsion model predictions and experimental measurements of the aeration effect on the driving pressure: $(+)$ experimental measurements, $(---) \varepsilon_{\mathrm{c}}>0.54 \approx \varepsilon_{\mathrm{mf}}$.

determined experimentally. A fluidization velocity of the emitter of at least the minimum bubbling velocity and an aeration velocity in the tube of at least five times the minimum bubbling velocity (150 NL. $\mathrm{h}^{-1}$ of air flow rate injected in the aeration nozzle) are required to ensure a steady flow of solid in the tubes. The even distribution of the total solid flow rate between the tubes requires both an emitter bed fluidization velocity higher than the minimum bubbling velocity and the equal aeration of each tube.

A description of the suspension flow based on the bubbleemulsion model formalism and adapted to take into account the particle entrainment by bubble wake was evaluated in front of driving pressure predictions. The singular flow generated in the tubes is well described by this model. Thus, this model can be used as design tool.

Based on the previous work know-how and the certitude of the hydrodynamic feasibility, a 1-tube hot mock-up was built. This mock-up will allow the determination of wall-to-particles heat exchange coefficient up to $800{ }^{\circ} \mathrm{C}$ under controlled hydrodynamic and heating conditions.

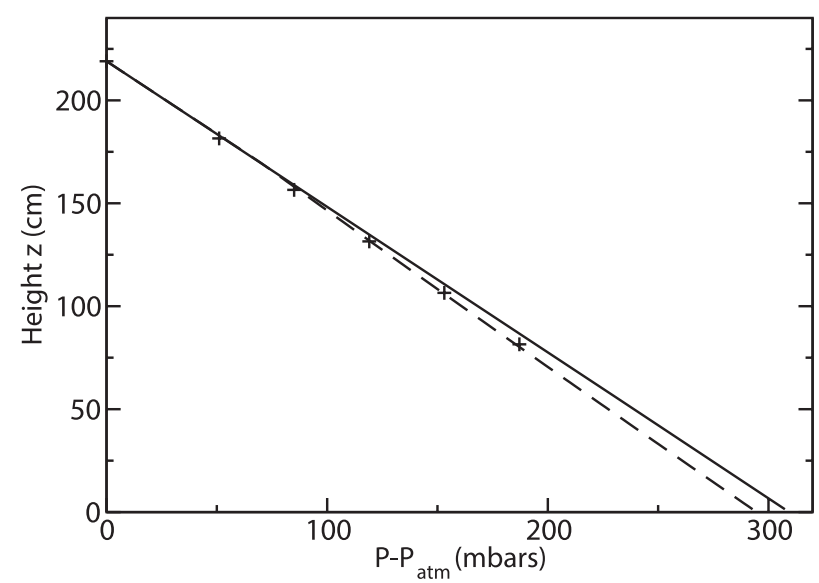

Figure 27. Effect of gas phase compressibility on model predictions and comparison with experimentally determined axial pressure profile: $(+)$ experimental measurements, $(---) \rho_{\mathrm{g}}$ varies with pressure, $(-)$ $\rho_{\mathrm{g}}=\rho_{\mathrm{g}}\left(\mathrm{T}=293 \mathrm{~K}, \mathrm{P}_{\mathrm{atm}}\right)$.

\section{NOMENCLATURE}

$\mathrm{A}_{\mathrm{c}} \quad$ tube cross section area $\left[\mathrm{m}^{2}\right]$

$\mathrm{c}_{\mathrm{p}, \mathrm{m}} \quad$ mass specific heat $\left[\mathrm{J} . \mathrm{kg}^{-1} \cdot \mathrm{K}^{-1}\right]$

$\mathrm{d}_{\mathrm{b}} \quad$ bubble diameter [m]

$\mathrm{d}_{\mathrm{bm}} \quad$ maximum bubble diameter $[\mathrm{m}]$

$\mathrm{d}_{32} \quad$ particle Sauter diameter $[\mu \mathrm{m}]$

$f_{w} \quad$ ratio of the wake volume fraction over the bubble volume fraction

$\mathrm{F}_{\mathrm{g}} \quad$ total gas flow rate flowing through a tube $\left[\mathrm{kg} \cdot \mathrm{h}^{-1}\right]$

$\mathrm{F}_{\mathrm{p}} \quad$ solid feeding flow rate $\left[\mathrm{kg} \cdot \mathrm{h}^{-1}\right]$

$\mathrm{F}_{\mathrm{p}}$, tube solid flow rate per tube $\left[\mathrm{kg} \cdot \mathrm{h}^{-1}\right]$

g gravity constant $\left[\mathrm{m} . \mathrm{s}^{-2}\right]$

$\mathrm{L}_{\mathrm{C}} \quad$ tube length $[\mathrm{m}]$

$\mathrm{P} \quad$ gas pressure $[\mathrm{Pa}]$

$\mathrm{P}_{\mathrm{atm}} \quad$ atmospheric pressure [mbars]

$\mathrm{P}_{\mathrm{fb}} \quad$ freeboard pressure of the emitter bed [mbars]

$P_{\text {in }} \quad$ inlet pressure of the tube [mbars]

$P_{\text {out }} \quad$ outlet pressure of the tube [mbars]

$\mathrm{Q}_{\mathrm{ae}} \quad$ aeration flow rate $\left[\mathrm{NL} . \mathrm{h}^{-1}\right]$

$\mathrm{Q}_{\mathrm{bt}} \quad$ gas flow rate exchange between the bed and a tube $\left[\mathrm{NL} . \mathrm{h}^{-1}\right.$ ]

$\mathrm{Q}_{\mathrm{f}} \quad$ fluidization flow rate $\left[\mathrm{NL} \cdot \mathrm{h}^{-1}\right]$

$\mathrm{Q}_{\mathrm{He}} \quad$ helium flow rate [NL.h ${ }^{-1}$ ]

$\mathrm{u}_{\mathrm{ae}} / \mathrm{U}_{\mathrm{ae}} \quad$ interstitial/superficial aeration velocity $\left[\mathrm{m} . \mathrm{s}^{-1}\right]$

$\mathrm{u}_{\mathrm{g}} \quad$ interstitial gas velocity $\left[\mathrm{m} . \mathrm{s}^{-1}\right]$

$\mathrm{u}_{\mathrm{g}, \mathrm{e}} \quad$ interstitial gas velocity in the emulsion $\left[\mathrm{m} . \mathrm{s}^{-1}\right]$

$\mathrm{u}_{\mathrm{p}} \quad$ particle velocity $\left[\mathrm{m} . \mathrm{s}^{-1}\right.$ ]

$\mathrm{u}_{\mathrm{p}, \mathrm{e}} \quad$ particle velocity in the emulsion $\left[\mathrm{m} . \mathrm{s}^{-1}\right.$ ]

$\mathrm{u}_{\mathrm{mb}} / \mathrm{U}_{\mathrm{mb}}$ interstitial/superficial minimum bubbling velocity $\left[\mathrm{m} . \mathrm{s}^{-1}\right]$

$\mathrm{u}_{\mathrm{mf}} / \mathrm{U}_{\mathrm{mf}} \quad$ interstitial/superficial minimum fluidization velocity $\left[\mathrm{m} . \mathrm{s}^{-1}\right]$

$\mathrm{u}_{\mathrm{sl}} \quad$ slip velocity $\left[\mathrm{m} . \mathrm{s}^{-1}\right]$

$\mathrm{U}_{\mathrm{b}} \quad$ bubble velocity $\left[\mathrm{m} . \mathrm{s}^{-1}\right.$ ]

$\mathrm{U}_{\mathrm{ch}} \quad$ chocking velocity $\left[\mathrm{m} . \mathrm{s}^{-1}\right]$

$\mathrm{U}_{\mathrm{f}} \quad$ fluidization velocity of the emitter bed $\left[\mathrm{m} . \mathrm{s}^{-1}\right.$ ]

$\mathrm{U}_{\mathrm{g}} \quad$ superficial gas velocity in the tube $\left[\mathrm{m} . \mathrm{s}^{-1}\right.$ ]

$\mathrm{U}_{\mathrm{mp}} \quad$ minimum velocity for dilute pneumatic conveying $\left[\mathrm{m} . \mathrm{s}^{-1}\right]$

$\mathrm{U}_{\mathrm{ms}} \quad$ minimum slugging velocity $\left[\mathrm{m} . \mathrm{s}^{-1}\right]$

$\mathrm{U}_{\mathrm{p}} \quad$ superficial particle velocity in the tube $\left[\mathrm{m} . \mathrm{s}^{-1}\right]$

$\mathrm{y}_{\mathrm{He}} \quad$ helium volume fraction

$\mathrm{z} \quad$ height in the tube $[\mathrm{m}]$

$\delta_{\mathrm{b}} \quad$ bubble volume fraction

$\Delta \mathrm{P}_{\text {bed }} \quad$ emitter bed hydrostatic pressure [mbars]

$\Delta \mathrm{P}_{\text {drive }} \quad$ driving pressure of the solid flow [mbars]

$\Delta \mathrm{P}_{\text {friction }}$ gas pressure drop by wall-to-particle friction [mbars]

$\Delta \mathrm{P}_{\text {hydro }} \quad$ hydrostatic gas pressure drop [mbars]

$\varepsilon \quad$ void fraction

$\varepsilon_{\mathrm{e}} \quad$ emulsion void fraction

$\varepsilon_{\mathrm{g}} \quad$ void fraction in mesh cells

$\varepsilon_{\mathrm{mb}} \quad$ minimum bubbling suspension void fraction

$\varepsilon_{\mathrm{mf}} \quad$ minimum fluidization suspension void fraction

$\varepsilon_{\mathrm{p}} \quad$ solid fraction in mesh cells

$\lambda \quad$ thermal conductivity $\left[\mathrm{W} \cdot \mathrm{m}^{-1} \cdot \mathrm{K}^{-1}\right]$

$\rho_{\mathrm{g}} \quad$ gas density $\left[\mathrm{kg} . \mathrm{m}^{-3}\right]$

$\rho_{\mathrm{p}} \quad$ particle density $\left[\mathrm{kg} \cdot \mathrm{m}^{-3}\right.$ ]

\section{ACKNOWLEDGEMENTS}

This work was first funded by French CNRS (Energy Programme) and was developed in the frame of the European CSP2 Project - 
Concentrated Solar Power in Particles. This project has received funding from the European Union's Seventh Programme for research, technological development and demonstration under grant agreement $\mathrm{N}^{\circ} 282932$.

\section{REFERENCES}

[1] C. Singer, R. Buck, R. Pitz-Paal, H. Müller-Steinhagen, J. Sol. Energy Eng. 2010, 132, 4.

[2] J. M. Lata, M. Rodriguez, M. A. de Lara, J. Sol. Energy Eng. 2008, 130, 21002.

[3] J. I. Ortega, J. I. Burgaleta, F. M. Tellez, J. Sol. Energy Eng. 2008, 130, 24501.

[4] J. Pacio, T. Wetzel, Sol. Energy 2013, 93, 11.

[5] http://www.csp2-project.eu/home.html.

[6] US 4290779 (1981) S. A. Qader, F. Robert.

[7] G. Flamant, G. Olalde, Sol. Energy 1983, 31, 463.

[8] A. Steinfeld, Sol. Energy 2005, 78, 603.

[9] G. Flamant, D. Gauthier, H. Benoit, J. L. Sans, R. Garcia, B. Boissière, R. Ansart, M. Hemati, Chem. Eng. Sci. 2013, 102, 567.

[10] E. Tavares dos Santos, Etude Experimentale et Numérique du Soutirage des Particules d'un Lit Fluidisé. Application au Cas Industriel du FCC, PhD thesis, Toulouse National Institute of Technology, Toulouse 2010.

[11] R. Watson, R. Thorpe, J. Davidson, Powder Technol. 2012, 224, 155.

[12] G. Turzo, Transport par Fluidisation en Phase Hyperdense: Amélioration Technologique, Modélisation et Dimensionnement, PhD thesis, Toulouse National Institute of Technology, Toulouse 2013.

[13] Y. Li, M. Kwauk, "The dynamics of fast fluidization," Fluidization, J. R. Grace, J. M. Matsen, Eds., Fluidization Plenum, New York 1980, p. 537.

[14] T. Hirama, H. Takeuchi, T. Chiba, Powder Technol. 1992, 70, 215.

[15] F. A. Zenz, Ind. Eng. Chem. 1949, 41, 2801.

[16] A. M. Squires, M. Kwauk, A. A. Avidan, Science 1985, 230, 1329.

[17] H. Bi, J. Grace, Int. J. Multiphase Flow 1995, 21, 1229.

[18] F. Zenz, Chemical Engineering 1953, 60, 176.

[19] D. Bataille-Durupt, Analyse du Fonctionnement en Régime Permanent et en Régime Transitoire d'un Echangeur de Chaleur Gaz-Solide à Lits Fluidisés Multi-Etagés, PhD thesis, Toulouse National Institute of Technology, 1986.

[20] G. Flamant, Transferts de Chaleur Couplés dans les Lits Fluidisés à Haute Température: Application à la Conversion Thermique de l'Energie Solaire, Es-Science $\mathrm{PhD}$ thesis, Toulouse National Institute of Technology, 1985.

[21] P. Rowe, B. Partridge, Chem. Eng. Res. Des. 1997, 75, 116.

[22] J. F. Davidson, D. Harrison, Fluidized Particles, Cambridge University Press, London 1963.

[23] S. Mori, C. Wen, AIChE J. 2010, 56, 1163. 